\title{
1 A Lagrangian model for phototaxis-induced thin layer formation
}

2

3 HidekatsuYamazaki $^{1 *}$, Chris Locke ${ }^{1}$, Lars Umlauf ${ }^{2}$, Hans Burchard ${ }^{2}$, Takashi Ishimaru ${ }^{1}$

4 and Daniel Kamykowski ${ }^{3}$

$5 \quad{ }^{1}$ Faculty of Marine Science, Tokyo University of Marine Science and Technology, 5-7,

6 Konan 4, Minato-ku, Tokyo 108-8477, Japan.

7

$8 \quad{ }^{2}$ Baltic Sea Research Institute Warnemuende, Seestrasse 15,

9 D-18119 Rostock-Warnemuende, Germany

10

${ }^{3}$ Marine, Earth and Atmospheric Sciences, North Carolina State University, Raleigh, 12 NC 27695 USA

Corresponding author: Hidekatsu Yamazaki, hide@kaiyodai.ac.jp

Running head: Phototaxis thin layer model

Key words: Phytoplankton, Diurnal vertical migration, mixed layer, turbulence, Lagragian model 


\section{Abstract}

We have developed a Lagrangian model to investigate a potential mechanism based on phototaxis behavior of phytoplankton cells for the formation of thin layers. We assume that all cells follow a time-regulated diurnal vertical migration during which they experience photo-acclimation based on the Denman and Marra (1986) model. When a cell experiences stress due to strong light that exceeds a threshold level, the cell swims downward, away from the light. We applied the Lagrangian model to a one dimensional second order turbulence closure model that generates a realistic surface mixing condition for a given set of physical parameters, such as wind and optical water type. For the chosen swimming velocities and prescribed behavior, we found that, in coastal water type and Jerlov III type, thin layer formation takes place up to $5 \mathrm{~m} \mathrm{~s}^{-1}$ winds, while $10 \mathrm{~m} \mathrm{~s}^{-1}$ winds cause sufficiently strong mixing to prevent the formation of thin layer. We have also investigated the effects of changing the irradiance threshold for the onset of the photoinhibition, the initial density profile and random walk swimming. In conclusion, thin layer formation due to photoinhibition may be possible for a low value of photoinhibition threshold that may occur either due to upwelling or strong light exposure.

48 Key words: Phytoplankton, Diurnal vertical migration, mixed layer, turbulence, Lagrangian model 


\section{INTRODUCTION}

Phytoplankton thin layers are ubiquitous phenomena in coastal areas around the world. Thin layer thickness typically ranges from a few tens of centimeters to a few meters, in which the phytoplankton concentration is significantly higher than the background concentration (GEOHAB 2008). The structure is also horizontally extensive. Dekshenieks et al. (2001) mentioned that thin layers may extend horizontally for a few kilometers and persist for several days. Moline et al. (2010) observed that the bioluminescence decorrelation length scale for thin layers in Monterey Bay was about 3 kilometers. During the 2005 Layered Organization in the Coastal Ocean (LOCO) field program, extensive field surveys were conducted in Monterey Bay to study the dynamics of thin layers (Sullivan et al., 2010; Rines et al., 2010; Cheriton et al., 2010; Ryan et al. 2010). Thin layers are important from an ecological point of view. They often occur in stratified water columns and can have special importance related to the dynamics of Harmful Algal Blooms (HABs). The layer structure also plays a role in phytoplankton growth dynamics, sexual reproduction and prey-predator interactions. In this study we used the following operational definition of a thin layer (GEOHAB 2008):

1) It must have a minimum spatial coherency horizontally;

2) The feature must be less than three meters thick measured at half maximum intensity;

3) The magnitude of the property must be significantly higher (5 times) than background.

This operational definition is slightly different from the original definition suggested by Dekshenieks et al. (2001). In this paper we only deal with a one dimensional model, so 
condition (1) does not apply here.

Both physical and biological mechanisms contribute to thin layer formation. A shear induced straining mechanism has been proposed as one physically driven process (Franks, 1995; Birch et al., 2008). Buoyancy control is another such mechanism (Alldredge et al., 2002). Dinoflagellate swimming behavior (Kamykowski, 1995) also provides a biological vector that can interact with physical processes. Durham et al. (2009) proposed a combined mechanism between biological and physical processes where cells with gyrotaxis migrate in a sheared layer. Vertical migration of dinoflagellates formed a layer and the formation took place within a few hours (Sullivan et al., 2010), demonstrating that migration alone can cause thin layers to form. Stacey et al. (2007) discuss the formation and maintenance of thin layers in the presence of turbulent diffusion. Since turbulence broadens layers, convergence mechanisms must exist either physically or biologically. They considered shear, buoyancy and swimming as a potential mechanism. Steinbuck et al. (2009) found that directed swimming could be balanced against turbulent diffusion to maintain a thin layer. The time scale for formation was a few days, and layer breakdown due to turbulent mixing required around 10-100 hours. Sullivan et al. (2010) observed a persistent phytoplankton thin layer in Monterey Bay under various biological and physical conditions. Some layers were dominated by non-motile diatoms; on the other hand, some layers were dominated by highly motile dinoflagellate species. Internal waves may accumulate phytoplankton cells at an interface according to an Eulerian model study (Lennert-Cody and Franks, 1999, 2002), but the maximum concentration does not exceed twice the background concentration. Thus this mechanism is unlikely to create a thin layer that requires at least five times higher than the background concentration. An 
excellent review on thin layer formation mechanisms can be found in Durham and Stoker (2012).

A clear diel vertical migration was observed in an estuary using a fluorescence probe with signals dominated by dinoflagellates (Huon Estuary Study Team, 2000). Both field and laboratory data show that dinoflagellates may change their migration pattern depending on the intensity of light (Kamykowski et al., 1998, 1999). In this case, a cell experiences stress as photoinhibition when it is exposed to too much light. Marshall et al. (2000) reviewed mechanisms and models of photoinhibition. Ault (2000) observed that the marine dinoflagellate Prorocentrum triestinum migrated toward the surface during daylight hours until an adequate light level was reached, followed by a shift toward the mid-water column. Clegg et al. (2007) demonstrated that daylight was prominent among several environmental cues that influenced the vertical distribution of phytoplankton, such as dinoflagellates, especially in stratified water columns. individual cell trajectories is useful for studying the biological-physical coupling

114 problems. Flynn and Fasham (2002) studied the behavior of migratory cells using a 115 numerical model and found that cells remained at a subsurface location by migration, avoiding photoinhibition and behaviorally responded to changes in internal nutrient storage. Ralston et al. (2007) and Ji and Franks (2007) modeled swimming behavior as a function of the internal nutrient storage.

119 Visser and Thygesen (2003) and O'Brien et al. (2003) provided scale arguments for 120 formation of aggregate due to swimming under the influence of mixing, applying highly

121 idealized mixing conditions. Ross and Sharples $(2007,2008)$ developed a

122 sophisticated Lagrangian model to study phytoplankton motility in a stratified 
environment taking both light and nutrient factors into account. They focused on

tidally generated turbulence in the bottom boundary layer, but no forcing mechanisms at the surface, e.g. wind stress and convective processes, are integrated in the model. They also fixed the temperature profile by fixing stratification, so that the consequences of mixing are not considered.

128 In this study, we examine a simple, new potential scenario that may lead to the 129 formation of thin layers driven by vertical migration under the influence of 130 photoinhibition alone using realistic mixing conditions in the upper ocean. Although important previously proposed thin layer formation mechanisms include both light and nutrients (GEOHAB, 2008), the present model isolates a mechanism that focuses on the attenuation of solar radiation and dinoflagellate behavioral responses. This type of behavior represents a subset of thin layers that might occur in oligotrophic water columns. One example would be Karenia brevis in the Gulf of Mexico. The formation of biomass maxima often appear to be related to physical convergence mechanisms

137 (Janowitz and Kamykowski, 2006; Janowitz et al., 2008; Hetland and Campbell, 2007), not in situ growth. Nutrients are, therefore, not the major cause of the biomass

139 accumulation. Under proper photoacclimation circumstances, the biomass peak can 140 react to high incident radiation by migrating away from the surface.

\section{METHOD}

142 We have combined the biological behavior model described by Kamykowski and 143 Yamazaki (1997) and Nagai et al. (2003) with a state-of-the-art one-dimensional water 144 column mixed layer model (General Ocean Turbulence Model, GOTM) described by 145 Umlauf and Burchard (2005) in order to simulate realistic mixing conditions in the 146 upper ocean. We briefly describe the physical model first, and then the adapted 
147 biological behavior model is introduced.

\section{Physical model}

149 With the Boussinesq approximation, the Navier-Stokes equations are simplified into

150 two one-dimensional equations for vertical distribution of momentum when horizontal

151 homogeneity of the hydrographic background is assumed.

where the vertical coordinate is taken upward, $U$ is east-west mean velocity component (positive east), $V$ is north-south mean velocity component (positive north), and $f$ is the

Coriolis parameter. The eddy viscosity $A_{v}$ is obtained from the kinetic energy of turbulence $k$, the integral length scale $l$ and the stability parameter $c_{\mu}$, calculated by means of the turbulent closure of Canuto et al. (2001) as integrated into a two-equation turbulence closure model described by Burchard and Bolding (2001).

where $T$ is the local mean temperature, $I$ is solar radiation, $c_{p}$ is the heat capacity, and $\rho_{\mathrm{o}}$ the mean density of water. The vertical eddy diffusivity for heat/tracers $K_{v}$ is expressed in terms of $k, l$ and stability parameter $c_{\mu}{ }^{\prime}$. The solar radiation consists of an infrared part $(>780 \mathrm{~nm})$ and visible part $(400 \mathrm{~nm}<$ wavelength $<700 \mathrm{~nm})$ :

$$
I(z)=I_{0}\left\{R \exp \left(\frac{z}{\lambda_{1}}\right)+(1-R) \exp \left(\frac{z}{\lambda_{2}}\right)\right\}
$$


where $I_{o}$ is the surface value of solar radiation, the absorption length scale for infrared light is $\lambda_{1}$, for visible light is $\lambda_{2}$, and $R$ is a weighting factor which was empirically obtained from field data for the contribution of infrared light to solar radiation (Paulson and Simpson, 1977; Zaneveld and Spinrad, 1980). Table 1 provides the values we used. Phytoplankton cells make use of the visible light component, also called photosynthetically active radiation (PAR), to perform photosynthesis. $I_{P A R}$ is the second term of equation (6):

$$
I_{P A R}(z)=I_{0}(1-R) \exp \left(\frac{z}{\lambda_{2}}\right)
$$

UV radiation may also be considered, but this is a separate issue. The surface fluxes of momentum and heat are calculated according to the bulk formulae of Kondo (1975). The atmospheric conditions are listed in Table 2. The computation depth domain is $100 \mathrm{~m}$, and the hypothetical location is set to latitude $45^{\circ} \mathrm{N}$ and longitude $0^{\circ}$. All simulations started at 06:00 on June 20, a typical mid-summer day that has long daylight hours, chosen because dinoflagellates can dominate in stratified conditions during the summer. The long daylight hours cause high values for incident irradiance and the large inhibition in the cells producing the most pronounced effect in the swimming behavior avoidance of photoinhibition.

\section{Lagrangian model}

Dinoflagellate swimming behavior is simulated through the Lagrangian approach (Nagai et al., 2003; Visser, 1997). Though the simple addition of swimming speed and turbulent vector may be naïve (Karp-Boss et al., 2000), turbulent intermittency and differential responses to turbulence among different species suggest that the present approach remains a useful baseline. 
behavior. In this model, the $i^{\text {th }}$ particle at time step $n$ with depth $z_{i}(n)$ will be advanced by the formula:

$$
\mathrm{z}_{i}(n+1)=\mathrm{z}_{i}(n)+\delta z_{i}+B_{i}
$$

where the random walk step due to turbulent mixing is $\delta \mathrm{z}_{i}$, and $B_{i}$ is the biological step due to the specified swimming behavior. Each step is separated by $\delta t$ in time. The random step is expressed as:

$$
\delta z_{i}=K_{v}^{\prime}\left(\mathrm{z}_{i}(n)\right) \cdot \delta t+\mathrm{N}\left(0,2 K_{v}\left(\mathrm{z}_{i}(n)+\frac{1}{2} K_{v}^{\prime}((n)) \delta t\right) \delta t\right)
$$

where $\mathrm{N}(\cdot, \cdot)$ denotes a normally distributed random number generated with mean 0 and variance $2 K_{v}\left(\mathrm{z}_{i}(n)+\frac{1}{2} K_{v}^{\prime}\left(\mathrm{z}_{i}(n)\right) \delta t\right) \delta t$ where $K_{v}^{\prime}$ is a spatial derivative with respect to $z$. The first term of right hand side equation and the second term in $K_{v}(\cdot)$ are correction terms for the random walk to avoid articifial accumulation of particles toward low diffusivity regions (Hunter et al., 1993; Visser, 1997).

We applied the photoacclimation model described by Janowitz and Kamykowski (1991) and Kamykowski et al. (1994). The original photoresponse model was developed by Denman and Marra (1986). The photosynthesis versus light curve is a simple function of visible light intensity:

$$
\begin{aligned}
& P_{d}=P_{d m}\left(1-\mathrm{e}^{-I_{P A R} / E_{d}}\right) \\
& P_{l}=P_{l m}\left(1-\mathrm{e}^{-I_{P A R} / E_{l}}\right)
\end{aligned}
$$

where $P_{d}$ and $P_{l}$ are the instantaneous photosynthetic production values for dark adapted and light adapted cells respectively. $\quad P_{d m}$ and $P_{l m}$ are the maximum production for each condition. $E_{d}$ and $E_{l}$ are the thresholds of light saturation for photosynthesis. The linear response model with inhibition parameter $0 \leq Y \leq 1$ is expressed as:

$$
P=P_{d}+Y\left(P_{l}-P_{d}\right)
$$


217 the cell as:

$$
\frac{d Y}{\mathrm{~d} t}=\frac{1}{\gamma}(X-Y)
$$

219 where $\gamma$ is the response time-scale. Although the amount of production, $P$, is not used in

220 the model, we provided these equations (10-12) in order to show how $Y$ is related to the production. The local fully inhibited value $0 \leq X \leq 1$ as a function of irradiance is:

$$
X=1-\exp \left(-\left(\frac{\operatorname{Max}\left(I_{P A R}, E_{b}\right)-E_{b}}{E_{b}}\right)^{2}\right)
$$

where $E_{b}$ is a threshold value of inhibition.

We set the swimming behavior based on the state of photoinhibition in order to test if such a simple mechanism leads to thin layer formation. Dinoflagellate cells start in the ascending/descending swimming mode before sunrise/sunset (Kamykowski, 1981).

Thus, by assuming the presence of an internal clock, a phytoplankton cell moves toward the surface during the day, and downward during the night as per Yamazaki and Kamykowski (1991). However, when the cell experiences stress from photoinhibition, we set the direction of motion away from the surface. This operation can be done by changing the sign of swimming step when $Y$ exceeds a threshold value $Y_{T}$ :

$$
B=\left\{\begin{array}{l}
+W_{S} \delta \mathrm{t} \text { when time between } 600 \text { and } 1800 \text { and } Y<Y_{T} \\
-W_{S} \delta \mathrm{t} \text { when time between } 1800 \text { and } 600 \text { or } Y \geq Y_{T}
\end{array}\right.
$$

Additional random swimming behavior could be included here as well, but was excluded here since random walk for the particles due to small scale turbulence is considered. However, we examine how introducing additional randomness in $B$ modifies the results that are presented in discussion.

237 Janowitz and Kamykowski (1991) used $E_{l}=E_{d}=500 \quad\left(\mu \mathrm{mol} \mathrm{m} \mathrm{m}^{-2} \mathrm{~s}^{-1}\right)$, whereas 238 Kamykowski et al. (1994) used $E_{l}=E_{d}=750\left(\mu \mathrm{mol} \mathrm{m} \mathrm{m}^{-2} \mathrm{~s}^{-1}\right.$. These values change the 
total production but do not affect the photoinhibition behaviors that are modified by $E_{b}$ and $Y_{T}$. We have assigned the same value to $E_{b}$ as Nagai et al. (2003), namely 200 ( $\mu$

mol m $\mathrm{m}^{-2} \mathrm{~s}^{-1}$. This value is rather low, with the intention of emphasizing the sensitivity to photoinhibition. In order to test the sensitivity of this parameter, we will present a case study by setting higher values.

\section{Base Simulations}

At the start of a simulation, 10,000 cells are uniformly distributed between the surface and $100 \mathrm{~m}$. We would like to investigate whether or not the photoinhibition behavior leads to the formation of a thin layer, and in what way it appears and eventually disappears. We also examine what wind velocities are required to disturb the formation of a thin layer. In order to study these aspects, we perform simulations with variations of the following three variables, giving 27 different simulations: also conducted three day simulations with a variable wind condition. For the first 24 hours the wind speed was set to $3 \mathrm{~m} \mathrm{~s}^{-1}$, then the wind speed was increased to $10 \mathrm{~m} \mathrm{~s}^{-1}$ for the next 24 hours, and following this strong wind event, the wind speed was reduced back to $3 \mathrm{~m} \mathrm{~s}^{-1}$ for the last 24 hours. This mimics a calm weather condition after a 

hour simulations are reasonable.

We tested this wind condition for three different water types and three $Y_{T}$ threshold values, for a total of nine different scenarios. These water types are explained in Paulson and Simpson (1977) and also a similar explanation is provided in Zaneveld and Spinrad (1980). See Table 1 for the values used in this study.

RESULTS

\section{4 hour simulation}

Physics

Coastal water type

The initial surface temperature is $20^{\circ} \mathrm{C}$, and the temperature decreases to $19.9^{\circ} \mathrm{C}$ at $20 \mathrm{~m}$. The salinity is kept constant throughout the simulation. These combinations correspond to the initial $N^{2}$ of $10^{-5}\left(\mathrm{~s}^{-2}\right)$. When wind speed is set to $3 \mathrm{~m} \mathrm{~s}^{-1}$, the surface temperature reaches the maximum value of $21.7^{\circ} \mathrm{C}$ at sunset (Fig. 1.a). Due to continuous heating from solar radiation during daytime, the stratification in the surface layer is enhanced until sunset. After sunset, nighttime convection takes over and the upper layer is mixed, transporting heat to the lower layer, so the nighttime eddy diffusivity is higher than the daytime diffusivity (Fig. 2.a). A strong pycnocline is created at the base of convective mixed layer.

The surface mixed layer reaches about 5 meters depth during the day for a wind speed of $5 \mathrm{~m} \mathrm{~s}^{-1}$. The nighttime convection deepens the mixed layer slightly, thus the surface temperature is lower than during the $3 \mathrm{~m} \mathrm{~s}^{-1}$ wind case. A sharp pycnocline is created at roughly 5 meter depth (Fig. 1.b). As in the $3 \mathrm{~m} \mathrm{~s}^{-1}$ wind case, the diffusivity 
is higher at night (Fig. 2.b).

Although daylight heating elevates the surface temperature, strong mixing caused by $10 \mathrm{~m} \mathrm{~s}^{-1}$ winds diffuses heat deeper than $20 \mathrm{~m}$ into the water column (Fig. 2.c), and the surface temperature remains less than $20.4^{\circ} \mathrm{C}$ at the end of daylight hours. A combination of wind stresses and convection deepens the mixed layer further down into the water column. At the end of 24 hours simulation, a fairly uniform surface mixed layer is created (Fig. 1.c)

Jerlov I water type

Although the PAR penetrates deeper into the water, the infrared part is absorbed in the upper part of the water column. Therefore, only the surface water is heated up in absence of mixing. The simulation shows that the $3 \mathrm{~m} \mathrm{~s}^{-1}$ wind speed is not strong enough to mix the upper water column, and thus a surface mixed layer only a few meter deep is present due to nighttime convection by the end of the simulation (Fig. 1.d). Because of the much smaller value of $\lambda_{1}$, the maximum surface temperature $\left(22.0^{\circ} \mathrm{C}\right)$ is higher than that of the coastal case $\left(21.7^{\circ} \mathrm{C}\right)$. The intensity of turbulence in terms of the eddy diffusivity $\left(1.1 \times 10^{-4} \mathrm{~m}^{2} \mathrm{~s}^{-1}\right)$ is actually weaker than that of the coastal case $\left(1.2 \times 10^{-3} \mathrm{~m}^{2} \mathrm{~s}^{-1}\right)$ (Fig. 2.d). At the $5 \mathrm{~m} \mathrm{~s}^{-1}$ wind speed, mixing is beginning to diffuse the surface heat deeper into the water column, but the surface convective mixed layer

305 still remains at the end of simulation (Fig. 1.e). When wind speed is set to $10 \mathrm{~m} \mathrm{~s}^{-1}$, 306 the mixing is effective almost to $30 \mathrm{~m}$ depth. Nighttime convection also reaches as deep as $30 \mathrm{~m}$.

Jerlov III water type

Since the value of $\lambda_{1}$ is almost the same as in the Coastal case, the surface mixed layer is also about the same thickness. A sharp pycnocline is created at the base 
311 (roughly $2 \mathrm{~m}$ depth) of the nighttime convective mixed layer (Fig. 1.g). For a wind 312 speed of $5 \mathrm{~m} \mathrm{~s}^{-1}$, the mixed layer is similar to the $3 \mathrm{~m} \mathrm{~s}^{-1}$ case except the mixed layer

313 reaches as deep as $5 \mathrm{~m}$ (Fig. 1.h), whereas a $10 \mathrm{~m} \mathrm{~s}^{-1}$ winds speed generates strong

314 mixing so that the upper $20 \mathrm{~m}$ is well mixed during both daytime and nighttime (Fig.

315 1.i)

$316 \quad$ Particle distributions

317 Coastal water type with $3 \mathrm{~m} \mathrm{~s}^{-1}$ winds

318 For $Y_{T}=0.2$, particles start to accumulate at 0.1 day, and the group descends until the 319 mid-day (Fig. 3.a). A high concentration of phytoplankton appears in the afternoon, particularly toward the end of the day. The thick black line at the top shows the times where the layer fulfills the definition of thin layer as presented in the introduction of this study. The thin layer is enhanced toward the end of day, and migrates toward the surface where turbulence effectively mixes the previously elevated particle concentration. At sunset, these accumulated particles descend in a group due to the change in the migration mode from ascending to descending. The particles descend coherently, so a straight strip appears in the figure. Considering the fact that each cell swims at a same speed, this is an artificial consequence. Thus we consider a case with a random swimming in discussion section.

329 Cases $Y_{T}=0.5$ (Fig. 3.b) and 0.8 (Fig. 3.c) show similar patterns but the thin layers appears at a shallower depths since the inhibition levels are higher. This causes the $Y_{T}$

$331=0.8$ case to become slightly dispersed due to the increased mixing near the surface.

Coastal water type with $5 \mathrm{~m} \mathrm{~s}^{-1}$ winds

The basic patterns for each case are the same, except particles are dispersed more due to the increased level of mixing. Although some parts are identified as a thin layer, the 
structure is more dispersed and less dense $\left(\log _{10} \mathrm{~N}_{\mathrm{p}} \cong 2.6\right)$ in comparison to the high value $\left(\log _{10} \mathrm{~N}_{\mathrm{p}}>3\right)$ of the $3 \mathrm{~m} \mathrm{~s}^{-1}$ case. Fig. 3.d shows the $Y_{T}=0.2$ case and the other two cases (Fig. 3.e and f) with slightly thicker layers than in this case.

For all cases (Fig. 3.g, h, and i), strong mixing is dominating over the thin layer formation mechanism so particles do not exhibit any layer formation.

Jerlov I water type with $3 \mathrm{~m} \mathrm{~s}^{-1}$ winds

Jerlov I is a clear open water case, so solar radiation penetrates deep. When $Y_{T}=0.2$ accumulation does not occur until around mid-day, and the high concentration layer descends further until solar radiation decreases to a level where photoinhibition does not suppress the ascending mode. The layer switches direction from ascending to descending at sunset, and maintains the layer structure during the descent (Fig. 4.a).

Similar to the coastal case, both $Y_{T}=0.5$ and 0.8 show the same pattern as the $Y_{T}=0.2$ case, except the layer formation takes place at a slightly shallower depth due to the increased photoinhibition thresholds (Fig. 4.b and c).

Jerlov I water type with $5 \mathrm{~m} \mathrm{~s}^{-1}$ winds

Although the level of mixing intensity increased, the particles accumulate at the same depth as the $3 \mathrm{~m} \mathrm{~s}^{-1}$ case. A concentration of cells occurs much deeper than the penetration depth of wind mixing (Fig. 2.e), so there is no destruction of the layer by turbulent mixing. The formation depth for $Y_{T}=0.5$ and 0.8 are also the same as the 3 $\mathrm{m} \mathrm{s}^{-1}$ case (Fig. 4.e and $\mathrm{f}$ ).

Jerlov I water type with $10 \mathrm{~m} \mathrm{~s}^{-1}$ winds

Even with winds elevated to $10 \mathrm{~m} \mathrm{~s}^{-1}$, the mixing does not reach the layer formation depth, so the same pattern as in the weaker wind conditions is observed (Fig. 4.g, h and 
i).

Jerlov III water type $3 \mathrm{~m} \mathrm{~s}^{-1}$ winds

Although the total amount of heat provided by solar radiation is similar to the coastal case, the difference in the layer formation is almost twice as much because PAR penetration is deeper. For $Y_{T}=0.2$, particle accumulation is much thicker and roughly twice that of the equivalent coastal case (Fig. 5.a). The layer reaches the deepest depth around 0.3 day, then the entire layer ascends until sunset. Interestingly, two bands are visible in the layer; one appears at the top and another at the bottom of the layer. The cells in the top band are moved from deeper water, and those in the bottom band are moved from the shallower water column. The differing behavior is due to the lagging of the photoinhibition parameter $Y$ behind the local fully inhibited parameter $X$, as per equation (13). The whole layer starts to sink after sunset, maintaining shape during the descent. The same features are observed for $Y_{T}=0.5$, except the layer formation naturally takes place at a shallower depth (Fig. 5.b). When $Y_{T}$ is set to 0.8 , much tighter layer formation takes place in shallower water. Generally, when a layer forms at a shallow depth, the layer is tighter than the deeper cases for the Jerlov III light condition (Fig. 5.c)

Jerlov III water type $5 \mathrm{~m} \mathrm{~s}^{-1}$ winds

Since the layer formation for $Y_{T}=0.2$ takes place near $10 \mathrm{~m}$ depth, the wind mixing does not reach the thin layer (Fig. 5.d). However, both $Y_{T}=0.5$ and 0.8 show layer formation at a sufficiently shallow depth (above $10 \mathrm{~m}$ depth) for the layers to smear due to mixing (Fig. 5.e and f). Although some smearing happens for both of these cases, we still observed layers that satisfy the definition of thin layer 

mechanism, and particles do not exhibit any layer formation, as shown in Fig. 5.g, h and i.

\section{Multiple day conditions}

387

\section{Physics}

During the first 24 hours, a $3 \mathrm{~m} \mathrm{~s}^{-1}$ wind speed for the coastal case establishes a $4 \mathrm{~m}$ thick mixed layer. The strong wind of $10 \mathrm{~m} \mathrm{~s}^{-1}$ deepens the mixed layer below $10 \mathrm{~m}$ depth (Fig. 6). The mixed layer then remains after winds weaken to $3 \mathrm{~m} \mathrm{~s}^{-1}$, but the upper layer is heated during daytime and mixed during nighttime, creating another surface mixed layer.

The strong winds cause nearly the same thermal structure for both Coastal and Jerlov III case (Fig. 6.a and c). Nighttime convection reaches below $20 \mathrm{~m}$ for the Jerlov I case (Fig. 6.b). The convection for Coastal and Jerlov III cases penetrates as deep as 15 $\mathrm{m}$ depth, so the mixing is limited to about $15 \mathrm{~m}$ (Fig. 7).

\section{Particle distributions}

\section{Coastal}

At $Y_{T}=0.2$, the concentration of particles, formed at sunset of the first day, do not change until mixing effectively disperses the accumulated particles early on the second day. Some particles move coherently, but the structure is quickly destroyed by the strong wind. Another high concentration of particles re-forms during the calm weather condition on the third day. The formation is almost identical to the first 24 hour case (Fig. 8.a), except with slightly lower concentrations due to particles being thrown into deeper depths from the strong wind mixing. Again, both the $Y_{T}=0.5$ and 0.8 cases show similar results, except the thin layer features occur at shallower depths, depending 
on the photoinhibition threshold (Fig. 8.b and c).

Jerlov I

409 Since the layer formation takes place deeper in the water column, mixing does not 410 affect the layer structure. The concentration of the thin layer is in fact increasing all

411 the way through to the end of the third day of simulation as particles from above join 412 the layer. Basically the same features are observed for all $Y_{T}$, except that the depth of 413 the layer formation changes a bit (Fig. 8.d, e and f).

\section{Jerlov III}

415 Wider thin layers are observed than in the coastal cases, with the shapes corresponding 416 to the respective 24 hour simulations. Since the layers are formed at shallow depths, the strong mixing on the second day destroys the thin layer structures. The calm weather condition allows thin layers like those during the first 24 hours to re-form (Fig.

8.g). Similar features are observed in the $Y_{T}=0.5$ and 0.8 cases (Fig. 8.h and i)

\section{DISCUSSIONS}

\section{Base simulations}

Since Coastal and Jerlov III water types are similar in infrared penetration, the thermal structures created from mixing are also similar. However, the two water types

424 differ in the PAR penetration depth, and consequently there is a difference in cell concentration. Jerlov I corresponds to a clear open water condition. In this case, although the infrared part does not penetrate as much as the other cases, the visible light reaches significant depths and causes cell migration to deep waters. We will therefore discuss Coastal and Jerlov III water types together, and provide a separate discussion for the Jerlov I type water cases.

430 Coastal and Jerlov III 
Although the thermal structures are similar in both cases, the PAR penetration depth

432

433

434 for Jerlov III is twofold. Therefore, cell accumulation for Jerlov III takes place deeper in the water column than in the Coastal case. For the weak wind $\left(3 \mathrm{~m} \mathrm{~s}^{-1}\right)$ condition, both cases show thin layer formation that starts before the noon. The layer then moves deeper into the water column due to an increase in the solar radiation, and therefore photoinhibition, until noon. The layers then ascend toward the surface. For the coastal cases, during ascent the particle concentration of the layer increases and gets thinner toward the end of daylight hours. On the other hand, for Jerlov III cases, the thin layer has two clear peaks in the afternoon for $Y_{T}=0.2$ and 0.5 , and the thin layer is not enhanced during ascent. At the end of the day, all cells are set to descend, and thus concentrations present at the end of the day move together, descending at a constant speed. The nighttime thin layer feature is set by the distribution of cells at sunset, and thus may be too simplistic an outcome. However, the daytime cell behavior may be realistic when other control factors are not as strong as photoinhibition.

Although thin layers are created even at the $5 \mathrm{~m} \mathrm{~s}^{-1}$ wind condition, mixing begins to smear the layer structure for the Coastal water case. For Jerlov III water type, the thin layer is formed deeper in the water column and mixing is less effective at disturbing the thin layer. At $10 \mathrm{~m} \mathrm{~s}^{-1}$ wind speed, no layer formation is observed in either water type. In the variable wind simulations, the same patterns of thin layer formation corresponding to the 24 hour weak wind cases $\left(3 \mathrm{~m} \mathrm{~s}^{-1}\right)$ are repeated after one day of strong wind mixing $\left(10 \mathrm{~m} \mathrm{~s}^{-1}\right)$.

From these simulation results, thin layer formation due to photoinhibition behavior can be observed while winds are weak in Coastal and Jerlov III water conditions. The layer may descend until noon, and ascend towards the end of the day. This result is 
consistent with the observation of Ault (2000) where the band of maximum $P$. triestinum cell density shifted downward in response to a PAR increase and upward in response to a PAR decrease.

Jerlov I

Because PAR penetrates deep into the water column, thin layer formation takes place much deeper than the Coastal and Jerlov III cases. The layer formations are taking place below $30 \mathrm{~m}$ depth where turbulence due to surface wind stress is too weak to effectively counteract the swimming of the particles even at $10 \mathrm{~m} \mathrm{~s}^{-1}$, so wind mixing does not disturb the thin layer structures. Since mixing is not affecting layer formation, we expect the concentration of cells in the layer to increase as time passes, and indeed the multiple day simulations show this tendency. If dinoflagellates with this behavior exist in the open ocean, thin layer formation due to photoinhibition may occur deeper in the water column. To date, no such observation has been reported to the best of our best knowledge.

Although the open water case (Jerlov I) shows thin layer formation at a relatively deep depth, this scenario may not be realistic and may not be serious from a Harmful Algal Blooms (HABs) point of view. In coastal waters, the phytoplankton species, including dinoflagellates, may be distributed forming thin layers (e.g. GEOHAB 2008). Lasker (1978) states that thin layer of phytoplankton may be formed if wind speeds remain below $4 \mathrm{~m} \mathrm{~s}^{-1}$ during 4 consecutive days. HABs occur where waters are most stratified (GEOHAB 2008). Our model also shows that the $3 \mathrm{~m} \mathrm{~s}^{-1}$ wind speed case reveals a clear thin layer formation, particularly for the coastal water case (Fig. 3). In the rest of this section, we are going to focus our attention on this particular case and how the thin layer formation is modified from additional considerations. 


\section{Photoinhibition threshold $\mathrm{E}_{\mathrm{b}}$}

480 The photoinhibition threshold $E_{b}$ used in equation (14) is rather low in comparison

481

482

483 with previous studies. For instance, Kamykowski et al. (1994) used $500\left(\mu \mathrm{mol} \mathrm{m}^{-2} \mathrm{~s}^{-1}\right)$, although Janowitz and Kamykowski (1991) used $200\left(\mu \mathrm{mol} \mathrm{m}^{-2} \mathrm{~s}^{-1}\right)$. The P-I curves based on $E_{b}=200,300,400$ and $500\left(\mu \mathrm{mol} \mathrm{m}^{-2} \mathrm{~s}^{-1}\right)$ are shown in Fig. 9. Clearly the $E_{b}$ $=200$ case is light sensitive. As $E_{b}$ increases, the depth of thin layer formation shallows and, as a result, the thickness of the layer increases. When $E_{b}=500(\mu \mathrm{mol}$ $\mathrm{m}^{-2} \mathrm{~s}^{-1}$ ), no subsurface thin layer is created. The layer formation takes place at the surface, thus photoinhibition is ineffective at creating a thin layer (not shown). The current model requires a low value of $E_{b}$, such as $200\left(\mu \mathrm{mol} \mathrm{m}{ }^{-2} \mathrm{~s}^{-1}\right)$. When cells are brought up from a deep water column due to upwelling, dark adapted cells may exhibit such a low $E_{b}$ (Blasco, 1978). Another possibility is that cells exposed to high PAR for extended hours may approach the $200\left(\mu \mathrm{mol} \mathrm{m} \mathrm{s}^{-1}\right)$ case in the afternoon on sunny days (Marshall et al , 2000; see their Fig. 8). In fact, this model shows the thinnest layer formation in the afternoon. Nutrient deprivation may further enhance this tendency (Marshall et al., 2000).

\section{Spin up}

Since the initial temperature (density) profile with a constant gradient is rather artificial, we ran the model for 30 days to spin up the whole dynamic response until it showed no more temperature increase in the mixed layer. The surface mixed layer is nearly a uniform temperature at $27^{\circ} \mathrm{C}$ before sunrise; then daylight heating elevates the surface temperature up to $28.5^{\circ} \mathrm{C}$ toward the end of the daylight hours and enhances stratification within the mixed layer (Fig. 10b). After sunset, due to long wave heat loss from the surface, convective mixing is promoted, and the depth range of uniform 
temperature increases until sunrise. The spin up case shows a deeper surface mixed layer and stronger nighttime mixing than the original condition (Fig. 10a and b). The spin-up case also shows higher diffusivity than the original case (Fig. 10c and d). The thin layer formation takes place at time 0.19 days, slightly after the original case, but the depth of the layer remains the same (Fig. 11.c). The peak in the layer density moves toward the surface after mid-day ( 0.25 days). The layer density increases until surface mixing promotes homogenization of the layer. Although the layer for the spin up case is slightly less dense than the original case, the temporal evolution of the thin layer between the mid-day and sunset is the same as the original one. Thus, at $3 \mathrm{~m} \mathrm{~s}^{-1}$ the initial condition of the temperature profile does not alter the thin layer formation.

\section{$513 \quad$ Random swimming}

514 The cell step size is fixed to a constant value, so all cells move at the same speed. Although this assumption is often applied to the step size (Yamazaki and Kamykowski, 1991), this is not realistic. We attempted to modify the biological step size for each cell as follows:

$$
B=\left\{\begin{array}{l}
+R W_{S} \delta \mathrm{t} \text { when time between } 600 \text { and 1800, and } Y<Y_{T} \\
-R W_{S} \delta \mathrm{t} \text { when time between } 1800 \text { and } 600 \text {, or } Y \geq Y_{T}
\end{array}\right.
$$

where $R W_{s}$ follows the Gaussian distribution $\mathrm{N}\left(W_{s}, W_{s}^{2}\right)$. Therefore cells move at variable step sizes. For the original mixed layer simulation, the thin layer formation is almost identical and maintains the same layer density until the end of the daylight hours. Without the variable swimming speed, all cells move downward at the given speed so that the thin layer formation is not destroyed (Fig. 11.a). On the other hand, due to the random spread of swimming speeds for each particle, the variable step condition causes the thin layer to spontaneously break up at night when particles all switch to downward 
swimming (Fig. $11 \mathrm{~b}$ ). The same tendency for the spin up mixed layer simulation is observed for both the constant and the variable step size case (Fig. 11c,d). Thus the thin layer formation during daylight hours, particularly in the afternoon, is not affected either by changing the initial temperature profile or by introducing the variable swimming speed condition.

\section{Expected layer formation}

Since cells are forced to move to a specific depth where the photoinhibition becomes ineffective, one should be able to specify the expected thin layer depth from the original definition of the photoinhibition model. A dotted blue line in Fig. 12(a-d)i shows the expected photoinhibition depth and a large number of cells moving towards this depth. The formation of thin layer takes place at time 0.17 for the original case (Fig.12a) and at time 0.2 for the spin up case (Fig.12c). Since we defined the mixed layer depth based on a density difference between the surface value and the base of the mixed layer being $0.125 \mathrm{~kg} \mathrm{~m}^{-3}$, the mixed layer depth for the original case is quite deep at the beginning and shallows to roughly $4 \mathrm{~m}$ as time progresses. The spin up case shows a $\sim 5.5 \mathrm{~m}$ mixed layer until mid-day and shallows towards 4 m deep in the afternoon. Thus both cases show roughly the same mixed layer depth in the afternoon. The thickness of the thin layer for both the original case and the spin up case is about $1.4 \mathrm{~m}$, and the thickness is reduced until time 0.4 days. An expected thin layer thickness $l_{\text {swim }}$ is a function of the eddy diffusivity, $K_{v}$, and the swimming speed of cell, $W_{s}$ (Stacey et al, 2007):

$$
l_{\text {swim }}=\frac{K_{v}}{W_{s}}
$$

549 This value is less than $0.1 \mathrm{~m}$ for both cases until time 0.4 day. This length scale corresponds to the Peclet number Pe: 


$$
P e=\frac{W_{S} l_{s w i m}}{K_{v}}
$$

552 being unity. The layer cannot be less than $0.1 \mathrm{~m}$ on the average according to the 553 definition of $P e$.

554 Towards the end of daylight hours cells move up near the surface where turbulent

555 diffusion is no longer weak. Therefore the expected thin layer thickness increases

556 sharply. At time 0.5 days a large fraction of cells move near the surface due to reduced

557 photoinhibition effects, and thus the layer is no longer created by the photoinhibition.

558 The effective thin layer formation based on the photoinhibition is expected roughly

559 between times 0.2 and 0.4 days.

560 The distribution of cells within the thin layer is nearly Gaussian (Fig. $12 \mathrm{ii}$ ), but the

561 kurtosis is slightly less than 3 (the Gaussian kurtosis) indicating the distribution is flatter

562 than Gaussian. The thickness of the layer is nearly the same as twice the standard

563 deviation of the cell distribution. This is a reasonable approximation since the

564 distribution is nearly Gaussian.

\section{Conclusions and Summary}

566 The thin layer formation model is developed combining existing Lagrangian approaches using realistic one-dimensional water column model (GOTM). Thin layer formation due to photoinhibition is realistic although the model requires a low value of the photoinhibition threshold. Such low values may occur due either to upwelling or to strong light exposure. The concentration cells in the thin layer increases after mid-day and the depth of the layer shallows. This tendency is the same for all three

572 light conditions, but the coastal water case is particularly clear. Considering the link

573 between the thin layer and $\mathrm{HAB}$, the thin layer formation for the coastal water condition is the most important one. If one observes thin layer formation in coastal water and 
the layer moves towards the surface as time progresses after mid-day, the photoinhibition formation mechanism may be the driving force behind the layer. In summary, we have developed a model that demonstrates a simple yet effective thin layer formation mechanism, but the model does not account for other factors such as nutrients, bioshading, gyrotaxis and predation. These additional factors should be integrated in the next step.

\section{Acknowledgement}

Adam Mantei worked on the initial part of this simulation work; his efforts are much appreciated. This work originated from a Japan-Germany cooperative science program (A Lagrangian study of Algal Bloom in the Ocean Mixed Layer) sponsored by Japan Society for the Promotion of Science (JSPS) and The Deutsche Forschungsgemeinschaft (DFG, grant no. BU 1199/5-1). Currently, the Japanese side is supported by a Grant-in-Aid for Science Research (B2) 16310005 from Japan Society for the Promotion of Science. DK is funded by NSF grant OCE-0726271 'Benthic dinoflagellate migration (BenDiM): Occurrence and processes'.

\section{References}

Alldredge, A.L., Cowles, T.J., MacIntyre, S.,Rines, J. E. B., Donaghay, P. L., Greenlaw, C. F., Holliday, D. V., Dekshenieks, M. M., Sullivan, J. M. and Zaneveld, J. R. V. (2002) Occurrence and mechanisms of formation of a dramatic thin layer of marine snow in a shallow Pacific fjord. Mar. Ecol. Prog. Ser., 233, 1-12.

Ault, T.R. (2000) Vertical migration by the marine dinoflagellate Prorocent rumtriestinum maximises photosynthetic yield. Oecologia., 125, 466-475, doi: $10.1007 / \mathrm{s} 004420000472$. 
Birch, D.A., Young, W.R. and Franks, P.J. (2008) Thin layers of plankton: formation by

600 shear and death by diffusion. Deep-Sea Res. Part I., 55, 277--295,

601 doi:10.1016/j.dsr.2007.11.009.

602 Blasco, D. (1978) Observations on the diel migration of marine dinoflagellates off the

603 Baja California coast. Mar. Biol., 46, 41--47, doi: 10.1007/BF00393819.

604 Burchard, H. and Bolding, K. (2001) Comparative analysis of four second-moment

605 turbulence closure models for the oceanic mixed layer. J. Phys. Oceanogr., 31,

$606 \quad 1943-1968$.

607 Canuto, V.M., Howard, A., Cheng, Y., and Dubovikov, M.S. (2001) Ocean turbulence.

608 Part I: one point closure model. Momentum and heat vertical diffusivities. J. Phys.

$609 \quad$ Oceanogr., 31, 1413-1426.

610 Cheriton, O.M., McManus, M.A., Steinbuck, Stacey, M.T., and Sullivan, J.M. (2010)

611 Towed vehicle observations of thin layer structure and a low-salinity intrusion in

612 northern Monterey Bay, CA. Cont. Shelf Res.,, 30, 39-49

613 Clegg, M.R., Maberly, S.C. and Jones, R.I. (2007) Behavioral response as a predictor of 614 seasonal depth distribution and vertical niche separation in freshwater phytoplankton 615 flagellates. Limnol. Oceanogr., 52, 441-455.

616 Dekshenieks, M.M., Donaghay, P.L.,Sullivan, J.M., Rines, J.E.B., Osborn, T.R. and 617 Twardowski, M.S, (2001) Temporal and spatial occurrence of thin phytoplankton 618 layers in relation to physical processes. Mar. Ecol. Prog. Ser., 223, 61-71.

619 Denman, K.L. and Marra, J. (1986) Modelling the time dependent photoadaptation of 620 phytoplankton to fluctuating light. P.341--349. In J.C. J. Nihoul [ed.] Marine 621 interfaces ecohydrodynamics. Elsevier.

622 Durham, W.M., Kessler, J.O. and Stocker, R. (2009) Disruption of vertical motility by 

10.1126/science. 1167334 .

625

626

627

628

629

630

631

632

633

634

635

636

637

638

639

640

641

642

643

644

645

646

Durham, W.M. and Stocker, R. (2012) Thin phytoplankton layers: characteristics, mechanisms and consequences. Annu. Rev. Mar. Sei., 4, 21.1-21.31.

Flynn, K. and Fasham, M.J.R. (2002) A modeling exploration of vertical migration by phytoplankton. J. theor. Biol.,218, 471-484, doi: 10.1006/jtbi.2002.3093.

Franks, P.J.S. (1995) Thin layers of phytoplankton: A model of formation by near-inertial wave shear. Deep-Sea Res. Part I., 42, 75--91, doi: 10.1016/0967-0637(94)00028-Q.

GEOHAB (2008) Global Ecology and Oceanography of Harmful Algal Blooms, GEOHAB Core Research Project: HABs in Stratified Systems. Gentien, P.,Reguera, B., Yamazaki, H., Fernand, L., Berdalet, E., Raine, R. (Eds.) IOC and SCOR, Paris, France, and Newark, Delaware, USA, 59pp.

Hetland, R.D. and Campbell, L. (2007) Convergent blooms of Karenia brevis along the Texas coast. Geophys. Res. Let. 34, L19604, doi:10.1029/2007GL030474.

Hunter, J.R., Craig, P.D. and Phillips, H.F. (1993) On the use of random walk models with spatially variable diffusivity. J. Comput. Phys., 106, 366-376.

Huon Estuary Study Team. (2000) Huon Estuary Study, Environmental research for integrated catchment management and aquaculture. Final report to FRDC. Project 96/284, CSIRO Division Marine Research, Marine Laboratories, Hobart, Tasmania, Australia.

Janowitz, G.S. and Kamykowski, D. (1991) An Eulerian model of phytoplankton photosynthetic response in the upper mixed layer. J. Plank. Res., 13, 983-1002. Janowitz, G.S. and Kamykowski, D. (2006) Modeled Karenia brevis accumulation in 

(Special Issue), 177-188.

Ji, R. and Franks, P.J.S. (2007) Vertical migration of dinoflagellates: model analysis of

652

653

654

655

656

657

658

659

660

661

662

663

664

665

666

667

668

669

670

strategies, growth, and vertical distributions. Mar. Ecol. Prog. Ser., 344, 49--61.

Kamykowski, D. (1981) Dinoflagellate growth rate in water columns of varying turbidity as a function of migration phase with daylight. J. Plank. Res.,3, 357-367.

Kamykowski, D. (1995) Trajectories of autotrophic marine dinoflagellates.

J.Phyco.,31，200-208..

Kamykowski, D., Milligan, E.J. and Reed, R.E. (1998) Relationships between geotaxis/phototaxis and diel vertical migration in autotrophic dinoflagellates. J. Plank. Res., 20: 1781-1796.

Kamykowski, D., Milligan, E. J., Reed, R. E. and Liu, W. (1999) Geotaxis/phototaxis and biochemical patterns in Heterocapsa (=Cachonina) illdefina (Dinophyceae) during diel vertical migrations. J. Phycol. 35: 1397-1403.

Kamykowski, D. and Yamazaki, H. (1997) A study of metabolism-influenced orientation in the diel vertical migration of marine dinoflagellates. Limnol. Oceanogr., 42, 1189-1202.

Kamykowski, D., Yamazaki, H. and Janowitz, G.S. (1994) A Lagrangian model of phytoplankton photosynthetic response in the upper mixed layer. J. Plank. Res.,16, 1059-1069.

Karp-Boss, L., Boss, E. and Jumars, P.A. (2000) Motion of dinoflagellates in a simple shear flow. Limnol. Oceanogr., 45, 1594--1602. 
671

672

673

674

675

676

677

678

679

680

681

682

683

684

685

686

687

688

689

690

691

692

693

694

Kondo, J. (1975) Air-sea bulk transfer coefficients in diabatic conditions, Bound. Layer Meteor., 9, 91-112, doi: 10.1007/BF00232256.

Lasker, R. (1978) Fishing for anchovies off California. Mar. Poll. Bull., 9, 320-321

Lennert-Cody, C.E. and Franks, P.J.S. (1999) Plankton patchiness in high-frequency internal waves. Mar. Ecol. Prog. Ser. 186: 59-66.

Lennert-Cody, C.E. and Franks, P.J.S. (2002) Fluorescence patches in high-frequency internal waves. Mar. Ecol. Prog. Ser. 235: 29-42.

Marshall, H.L., Geider, R.J. and Flynn, K.J. (2000) A mechanistic model of photoinhibition. New Phytol., 145, 347-359.

Moline, M., Benoit-bird, K.J., Robbins,I.C., Schroth-Miller, M., Waluk, C. M. and Zelenke, B. (2010) Integrated measurements of acoustical and optical thin layers II: Horizontal length scales. Cont. ShelfRes.,30, 29-38.

Nagai, T., Yamazaki, H. and Kamykowski, D. (2003) A Lagrangian photoresponse model coupled with $2^{\text {nd }}$-order turbulence closure. Mar. Ecol. Prog. Ser., 265, 17-30.

O’ Brien, K.R., Ivey, G.N., Hamilton, D.P., Waite, A.M. and Vissser, P.M. (2003) Simple mixing criteria for the growth of negatively buoyant phytoplankton. Limnol.

$$
\text { Oceanogr., 48, 1326-1337. }
$$

Paulson, C.A. and Simpson, J. J. (1977) Irradiance measurements in the upper ocean, $J$. Phys. Oceanogr., 7, 952-956.

Ralston, D., McGillicuddy ,D.J., and Townsend, D.W. (2007) Asynchronous vertical migration and bimodal distribution of motile phytoplankton. J. Plankton Res.,29, $803-821$.

Rines, J.E.B., McFarland, M.N., Donaghay, P.L., and Sullivan, J.M. (2010)

Thin layers and species-specific characterization of the phytoplankton community in 
696

697

698

699

700

701

702

703

704

705

706

707

708

709

710

711

712

713

714

715

716

717

718

Ross and Sharples (2007) Phytoplankton motility and the competition for nutrients in the thermocline. Mar. Ecol. Prog. Ser. 347: 21-38, doi: 10.3354/meps06999.

Ross and Sharples (2008) Swimming for survival: A role of phytoplankton motility in a stratified turbulent environment. J. Mar. Syst. $\quad$ 70, 248-262

Ryan, J.P., McManus, M.A. and Sullivan, J.M. (2010) Interacting physical, chemical and biological forcing of phytoplankton thin-layer variability in Monetary Bay, California, Cont. Shelf Res., 30, 7-16

Stacey, M.T., McManus, M.A. and Steinbuck, J.V. (2007) Convergences and divergences and thin layer formation and maintenance. Limnol. Oceanogr., 52, $1523-1532$.

Steinbuck, J.V., Stacey, M.T., McManus, M.A., Cheriton, O. M. and Ryan, J. P. (2009) Observations of turbulent mixing in a phytoplankton thin layer: Implications for formation, maintenance, and breakdown. Limnol. Oceanogr., 54, 1353-1368

Sullivan, J.M., Donaghay, P.L. and Rines, J.E.B. (2010) Coastal thin layer dynamics: Consequences to biology and optics. Cont. Shelf Res., 30, 50-65

Umlauf, L. and Burchard, H. (2005) Second-order turbulence closure models for geophysical turbulence models. A review of recent work. Cont. Shelf. Res.,25, 795-827, doi: 10.1016/j.csr.2004.08.004.

Visser, A. (1997) Using random walk models to simulate the vertical distribution of particles in a turbulent water column. Mar. Ecol. Prog. Ser., 158: 275-281, doi: $10.3354 /$ meps 158275 .

Visser, A and Thygesen. (2003) Random motility of plankton: diffusive and aggregative contributions. J. Plank. Res.. 25, 9, 1157-1168. 
719 Yamazaki, H. and Kamykowski, D. (1991) The vertical trajectories of motile

720 phytoplankton in a wind-mixed water column. Deep-Sea Res.,38, 219-241, doi:

721 10.1016/0198-0149(91)90081-P.

722 Zaneveld., V., Spinrad W., and Roland. J. (1980) An arc tangent model of irradiance in

723 the sea. J. Geophys. Res.85, C9, 4919-4922. 


\section{Figures legends}

725

726

727

728

729

730

731

732

733

734

735

736

737

738

739

740

741

742

743

744

745

746

747

Figure 1 Temperature $\left({ }^{\circ} \mathrm{C}\right)$ distribution during 24 hour simulations for three different wind conditions and three different water types. Coastal water type for $3 \mathrm{~m} \mathrm{~s}^{-1}$ is a, 5 $\mathrm{m} \mathrm{s}^{-1}$ is $\mathrm{b}$, and $10 \mathrm{~m} \mathrm{~s}^{-1}$ is c; Jerlov I water type for $3 \mathrm{~m} \mathrm{~s}^{-1}$ is d, $5 \mathrm{~m} \mathrm{~s}^{-1}$ is e, and $10 \mathrm{~m} \mathrm{~s}^{-1}$ is $\mathrm{f}$; Jerlov III water type for $3 \mathrm{~m} \mathrm{~s}^{-1}$ is $\mathrm{g}, 5 \mathrm{~m} \mathrm{~s}^{-1}$ is h, and $10 \mathrm{~m} \mathrm{~s}^{-1}$ is $\mathrm{h}$.

Figure 2 Turbulent eddy diffusivity in terms of based 10 logarithm $\left(\mathrm{m}^{2} \mathrm{~s}^{-1}\right)$ during 24 hour simulations for three different wind conditions and three different water types. Coastal water type for $3 \mathrm{~m} \mathrm{~s}^{-1}$ is a, $5 \mathrm{~m} \mathrm{~s}^{-1}$ is b, and $10 \mathrm{~m} \mathrm{~s}^{-1}$ is c; Jerlov I water type for $3 \mathrm{~m} \mathrm{~s}^{-1}$ is d, $5 \mathrm{~m} \mathrm{~s}^{-1}$ is e, and $10 \mathrm{~m} \mathrm{~s}^{-1}$ is $\mathrm{f}$; Jerlov III water type for $3 \mathrm{~m} \mathrm{~s}^{-1}$ is g, $5 \mathrm{~m} \mathrm{~s}^{-1}$ is $\mathrm{h}$, and $10 \mathrm{~m} \mathrm{~s}^{-1}$ is $\mathrm{h}$.

Figure 3 Particle distributions for Coastal water type during 24 hour simulations.

Particle density was computed for each $0.25 \mathrm{~m}$ depth interval. Three different winds are applied: Top row is $3 \mathrm{~m} \mathrm{~s}^{-1}$, middle row is $5 \mathrm{~m} \mathrm{~s}^{-1}$, and bottom row is $10 \mathrm{~m} \mathrm{~s}^{-1}$. Also three different photoinhibition thresholds, $Y_{T}$, are applied: Left column is 0.2 , middle column is 0.5 , and right column is 0.8 . Thick black line at the top of each window show thin layer that follows the definition provided in Introduction.

Figure 4 Particle distributions for Jerlov I water type during 24 hour simulations. Three different winds are applied: Top row is $3 \mathrm{~m} \mathrm{~s}^{-1}$, middle row is $5 \mathrm{~m} \mathrm{~s}^{-1}$, and bottom row is $10 \mathrm{~m} \mathrm{~s}^{-1}$. Also three different photoinhibition thresholds, $Y_{T}$, are applied: Left column is 0.2 , middle column is 0.5 , and right column is 0.8 . Thick black line at the top of each window show thin layer that follows the definition provided in Introduction. White area 
shows no particle.

749

750

Figure 5 Particle distributions for Jerlov III water type during 24 hour simulations.

751

Three different winds are applied: Top row is $3 \mathrm{~m} \mathrm{~s}^{-1}$, middle row is $5 \mathrm{~m} \mathrm{~s}^{-1}$, and bottom

752

row is $10 \mathrm{~m} \mathrm{~s}^{-1}$. Also three different photoinhibition thresholds, $Y_{T}$, are applied: Left

753

column is 0.2 , middle column is 0.5 , and right column is 0.8 . Thick black line at the top of each window show thin layer that follows the definition provided in Introduction.

Figure 6 Temperature $\left({ }^{\circ} \mathrm{C}\right)$ distributions of multiple day simulations for Coastal water type (a), Jerlov I (b) and Jerlov III (c).

758

759

760

Figure 7 Turbulent eddy diffusivity in terms of based 10 logarithm $\left(\mathrm{m}^{2} \mathrm{~s}^{-1}\right)$ of multiple day simulations for Coastal water type (a), Jerlov I (b) and Jerlov III (c).

Figure 8 Particle distributions for multiple day simulations. Coastal water type is the top row, Jerlov I water type is the middle row, and Jerlov III water type is the bottom row. The left column is $Y_{T}=0.2$, the middle column is $Y_{T}=0.5$, and the right column is $Y_{T}=0.8$. Thick black line at the top of each window show thin layer that follows the definition of Dekshenieks et al. (2001).

767

Figure 9 Production and Light intensity (PI) curves for $E_{b}=200,300,400$ and $500 \mu \mathrm{mol}$ $\mathrm{m}^{-2} \mathrm{~s}^{-1}$ (left to right curve).

Figure 10 Temperature distribution over the one day simulations for the original case 
772 (a) and the spin up case (b). The corresponding eddy diffusivity for each case is shown 773 in (c) and (d).

774

775 Figure 11 Cell concentration over the one day simulations for the original case (a)

776 without random swimming and (b) with random swimming. The spin-up case

777 without random swimming is (c) and with random swimming is (d).

778

779 Figure 12 Four panels show the original case without random swimming (a),

780 the original case with random swimming (b), the spin-up case without

781 random swimming (c) and the spin-up case with random swimming (d). Each

782 panel contains I) the expected layer depth (blue dotted line), the depth of

783 mixed layer (green dotted line) and the identified thin layer (blue band); ii)

784 standard deviation of cell location (red line), skewness (green line) and

785 kurtosis (blue line); iii) the thin layer thickness (blue line) and the expected

786 thin layer (red line).

787

788 


\section{Tables}

790 Table 1 Optical properties of sea water ( $\lambda_{1}$ is for IR $\& \lambda_{2}$ is for PAR). These values are 791 taken from Paulson and Simpson (1977).

\begin{tabular}{|l|l|l|l|}
\hline Water types & $\lambda_{1}(\mathrm{~m})$ & $\lambda_{2}(\mathrm{~m})$ & $\mathrm{R}$ \\
\hline Coastal & 1.50 & 3.30 & 0.80 \\
\hline Jerlov I & 0.35 & 23.00 & 0.58 \\
\hline Jerlov III & 1.40 & 7.90 & 0.78 \\
\hline
\end{tabular}

792

793

794 Table 2 Atmospheric and initial conditions used in the simulations. The stratification

795 is specified by the buoyancy frequency, $N$.

\begin{tabular}{|l|l|l|}
\hline $\mathrm{W}_{\mathrm{x}}$ & West-East winds & $3,5,10 \mathrm{~m} \mathrm{~s}^{-1}$ \\
\hline $\mathrm{W}_{\mathrm{y}}$ & North-South winds & $0 \mathrm{~m} \mathrm{~s}^{-1}$ \\
\hline$T_{a}$ & Air Temperature & $20^{\circ} \mathrm{C}$ \\
\hline$P_{a}$ & Atmospheric pressure & $1013 \mathrm{hPa}$ \\
\hline$H u$ & Relative humidity & $75 \%$ \\
\hline$C l$ & Cloud cover & $1 \%$ \\
\hline$N_{\text {init }}^{2}$ & Initial $N^{2}$ & $10^{-5} \mathrm{~s}^{-2}$ \\
\hline$T_{o, \text { init }}$ & Initial surface temperature & $20^{\circ} \mathrm{C}$ \\
\hline
\end{tabular}


799 Table 3 Biological parameters used in the simulations

\begin{tabular}{|l|l|l|}
\hline$P_{d m}$ & Dark adapted maximum production & $50 \mathrm{pg}$-at O2/cell/hour \\
\hline$P_{l m}$ & Light adapted maximum production & $3 \mathrm{pg}$-at O2/cell/hour \\
\hline$E_{d}$ & Point of light saturation for dark & $163.04 \mathrm{~W} \mathrm{~m}^{-2}$ \\
\hline$E_{l}$ & Point of light saturation for light & $163.04 \mathrm{~W} \mathrm{~m}^{-2}$ \\
\hline$E_{b}$ & Threshold for inhibition & $43.48 \mathrm{~W} \mathrm{~m}^{-2}$ \\
\hline$W_{s}$ & Swimming speed & $0.0003 \mathrm{~m} \mathrm{~s}^{-1}$ \\
\hline$\gamma$ & Photoinhibition response time scale & 1 hour \\
\hline$Y_{T}$ & Threshold for swimming direction & $0.2,0.5,0.8$ \\
\hline
\end{tabular}



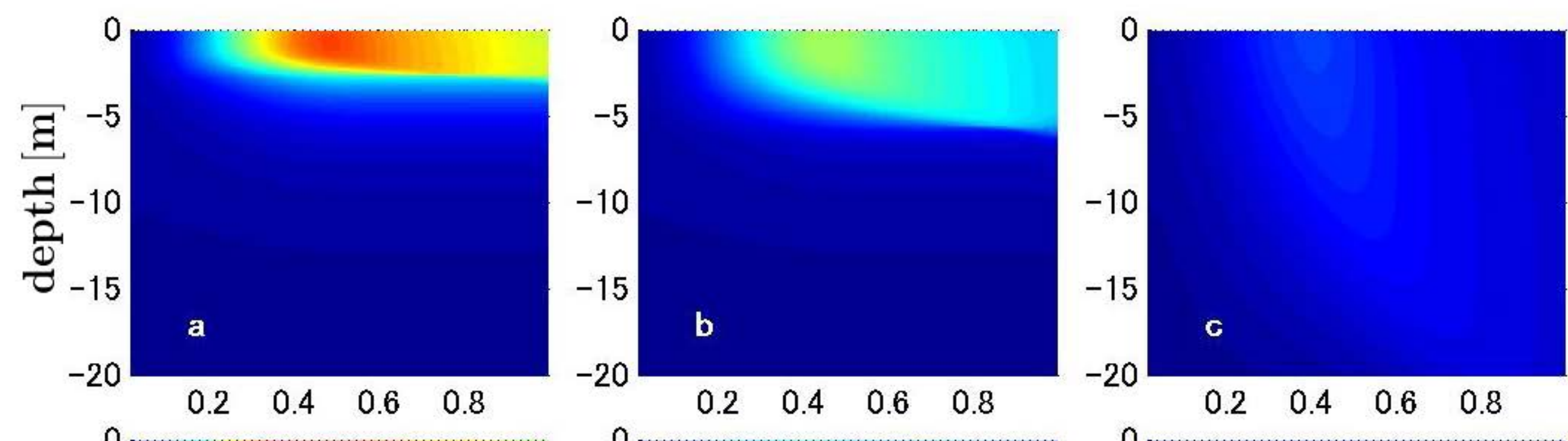

$\mathbf{T}\left[{ }^{\circ} \mathbf{C}\right]$
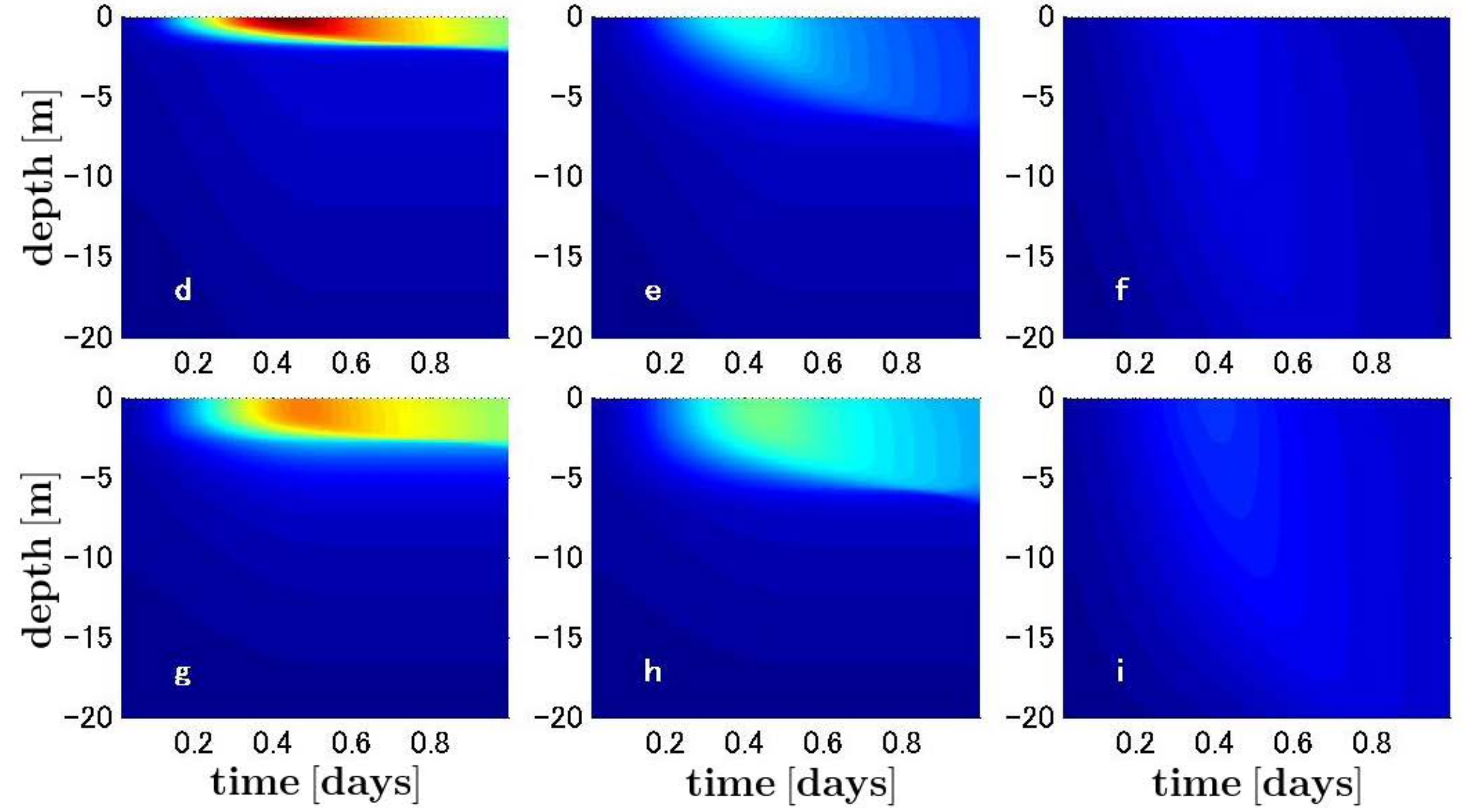
Figure 2
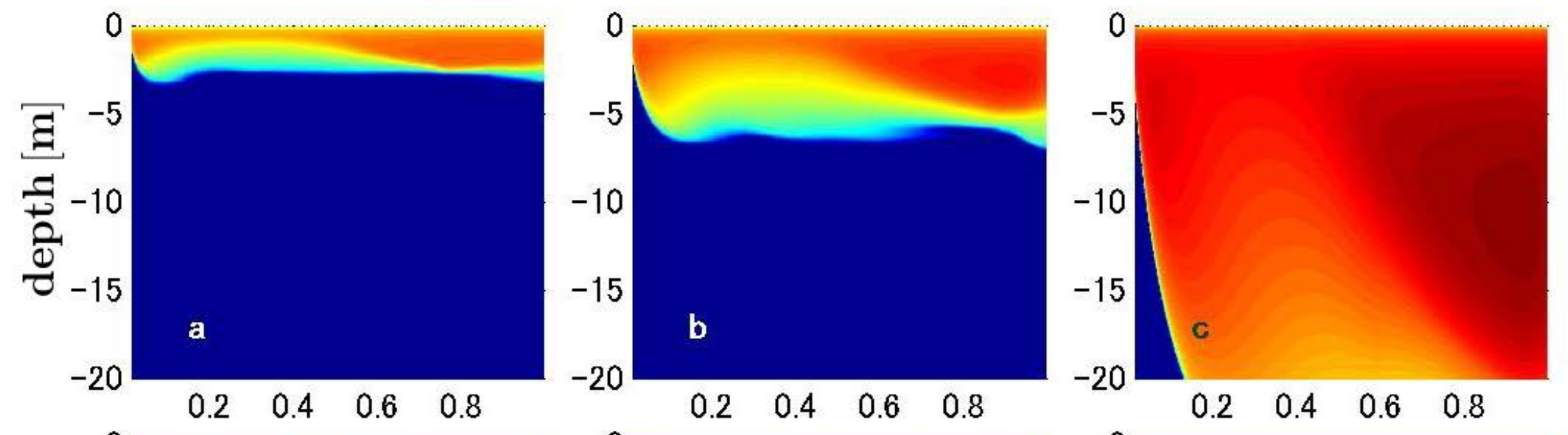

$\log _{10}\left(K_{\vee}\right)$
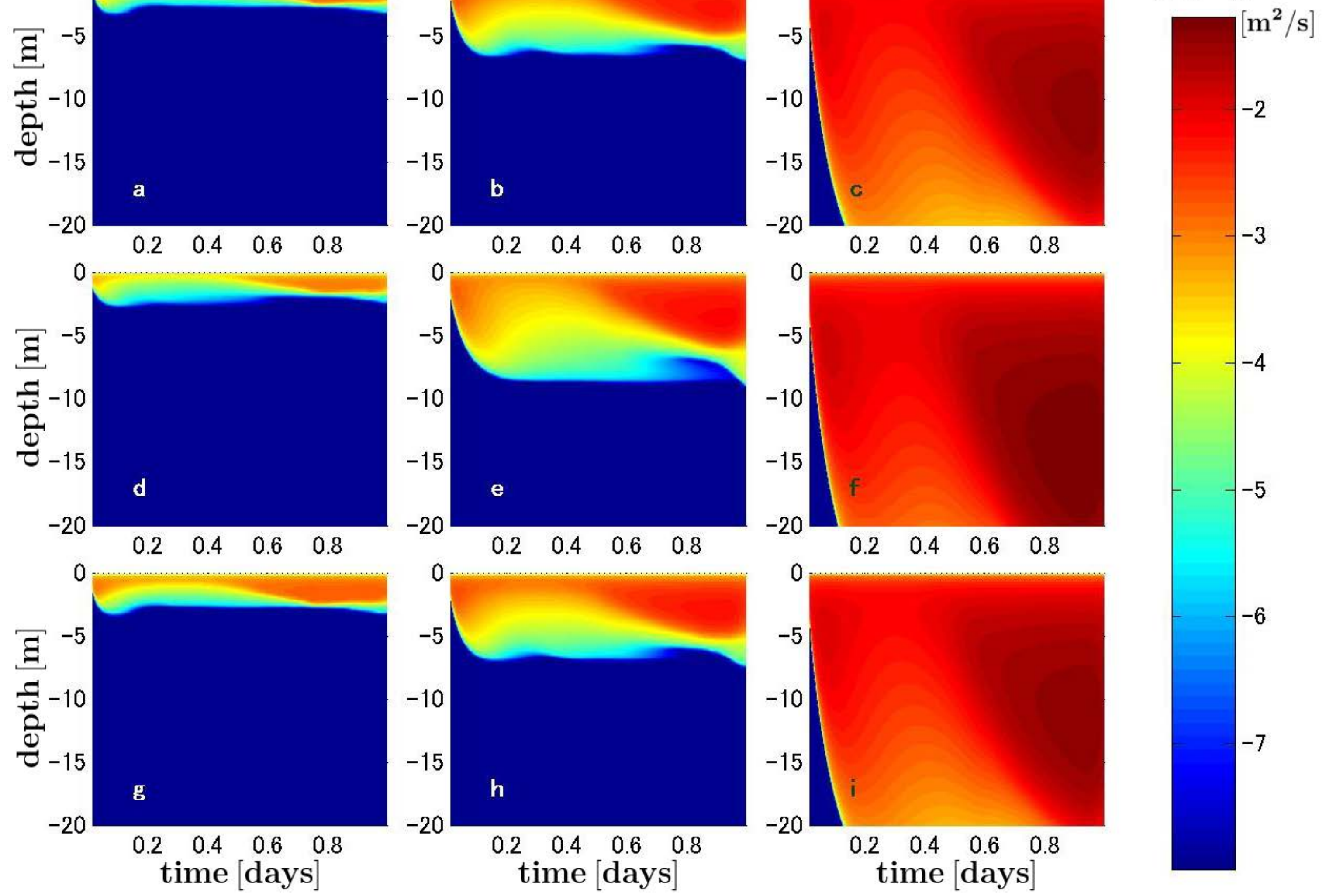
Figure 3
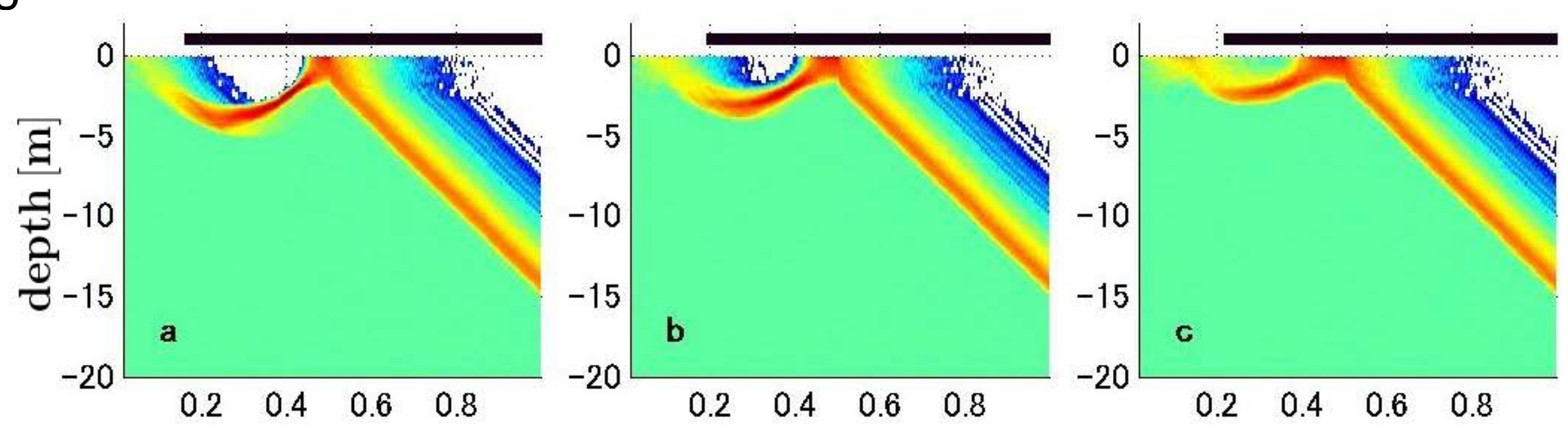

$\log _{10}\left(\mathrm{~N}_{\mathrm{p}}\right)$
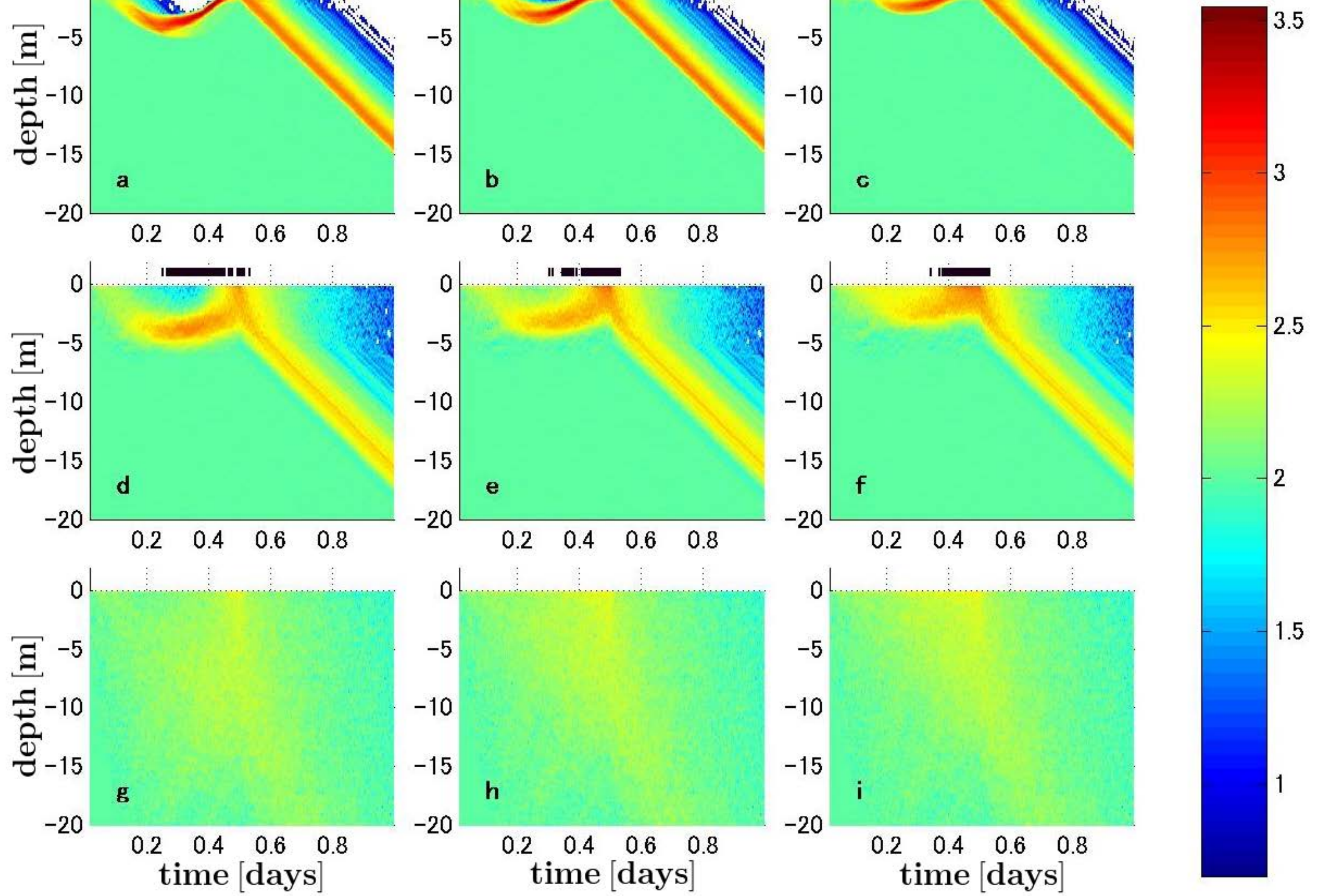
Figure 4
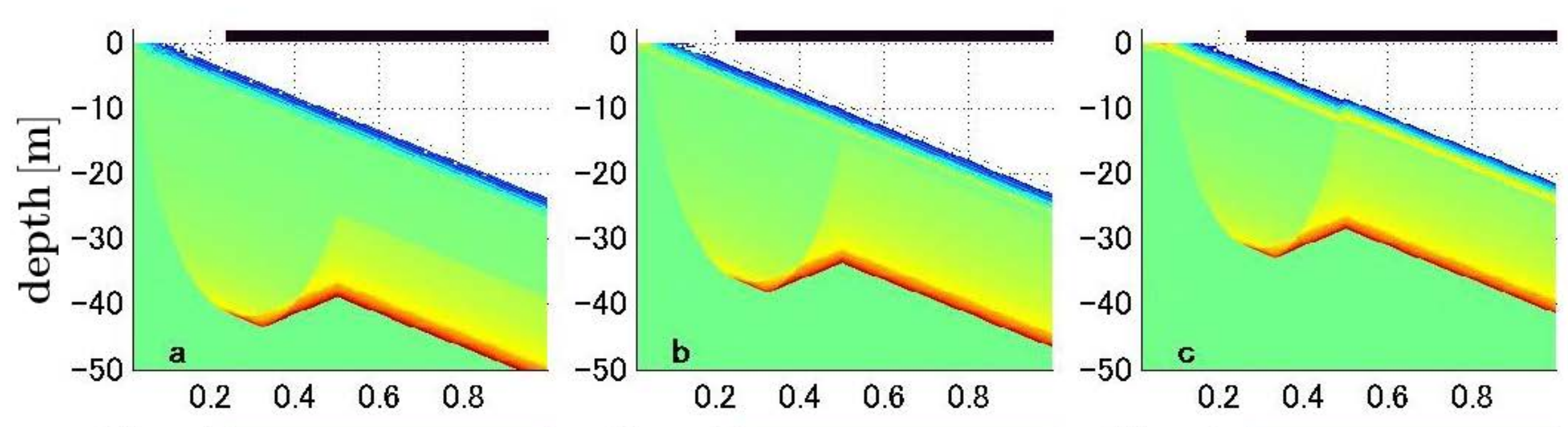

$\log _{10}\left(N_{p}\right)$
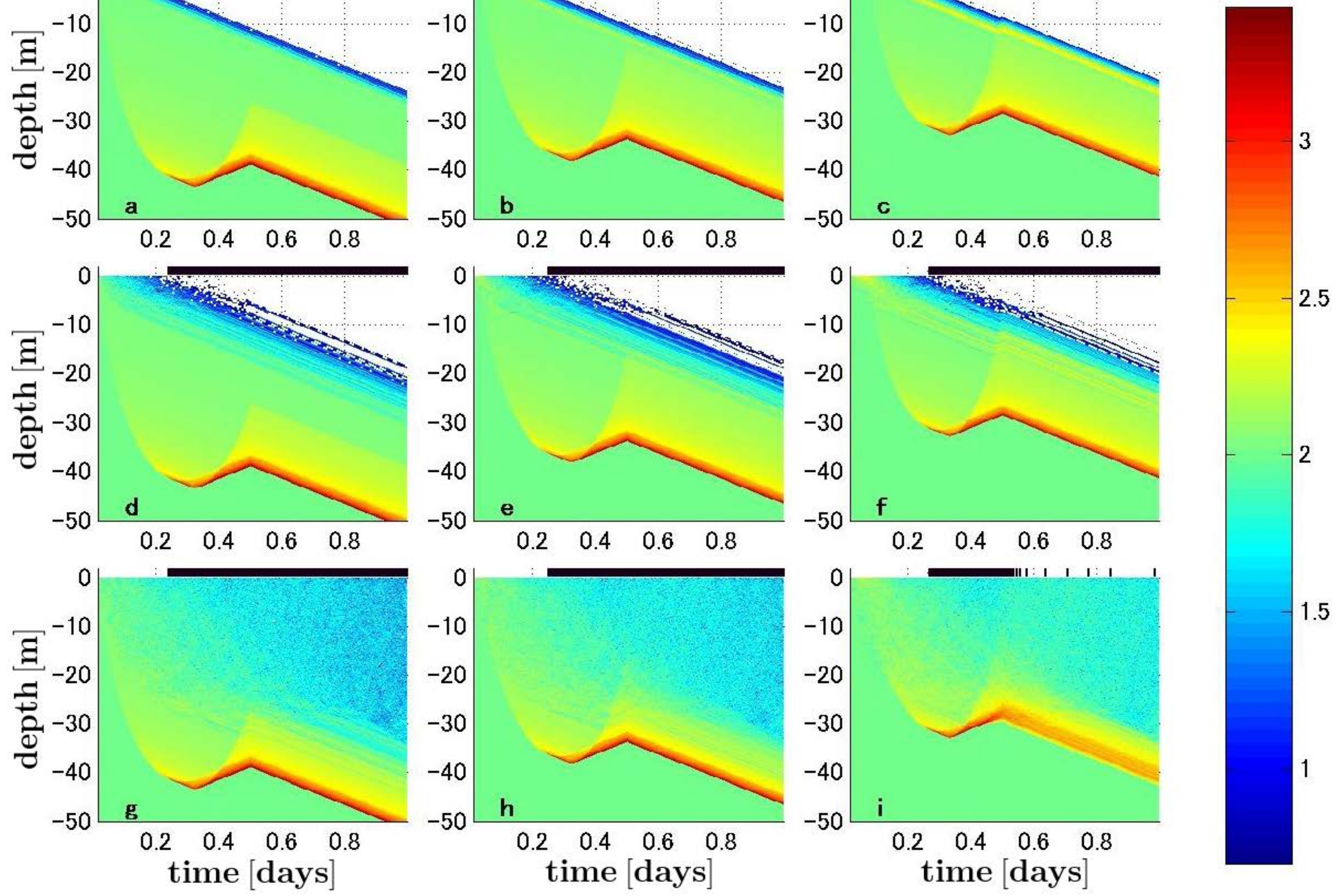
Figure 5
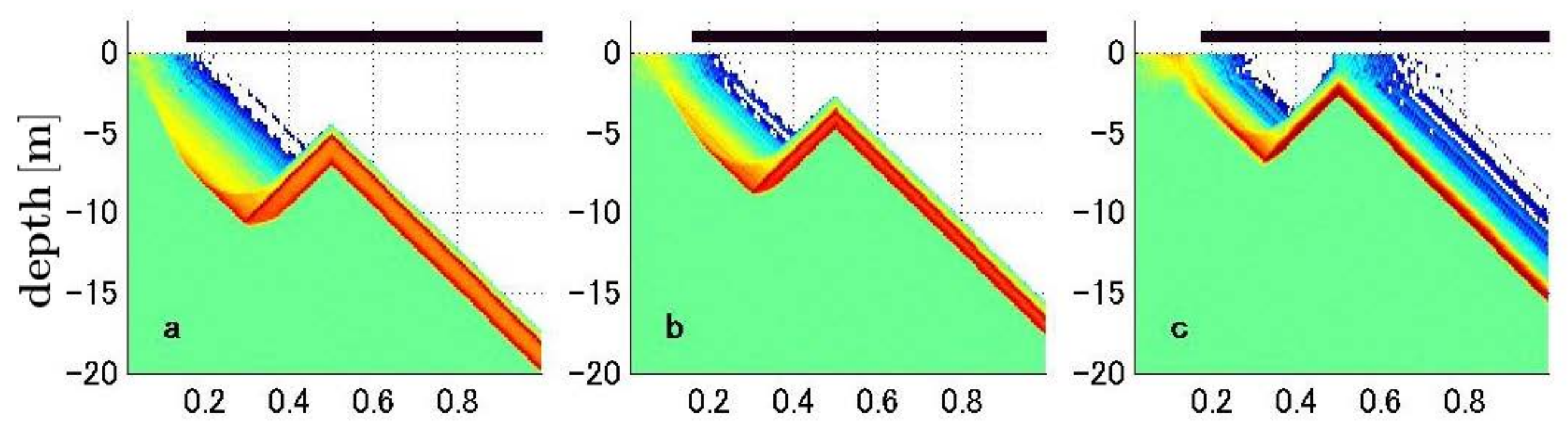

$\log _{10}\left(N_{p}\right)$
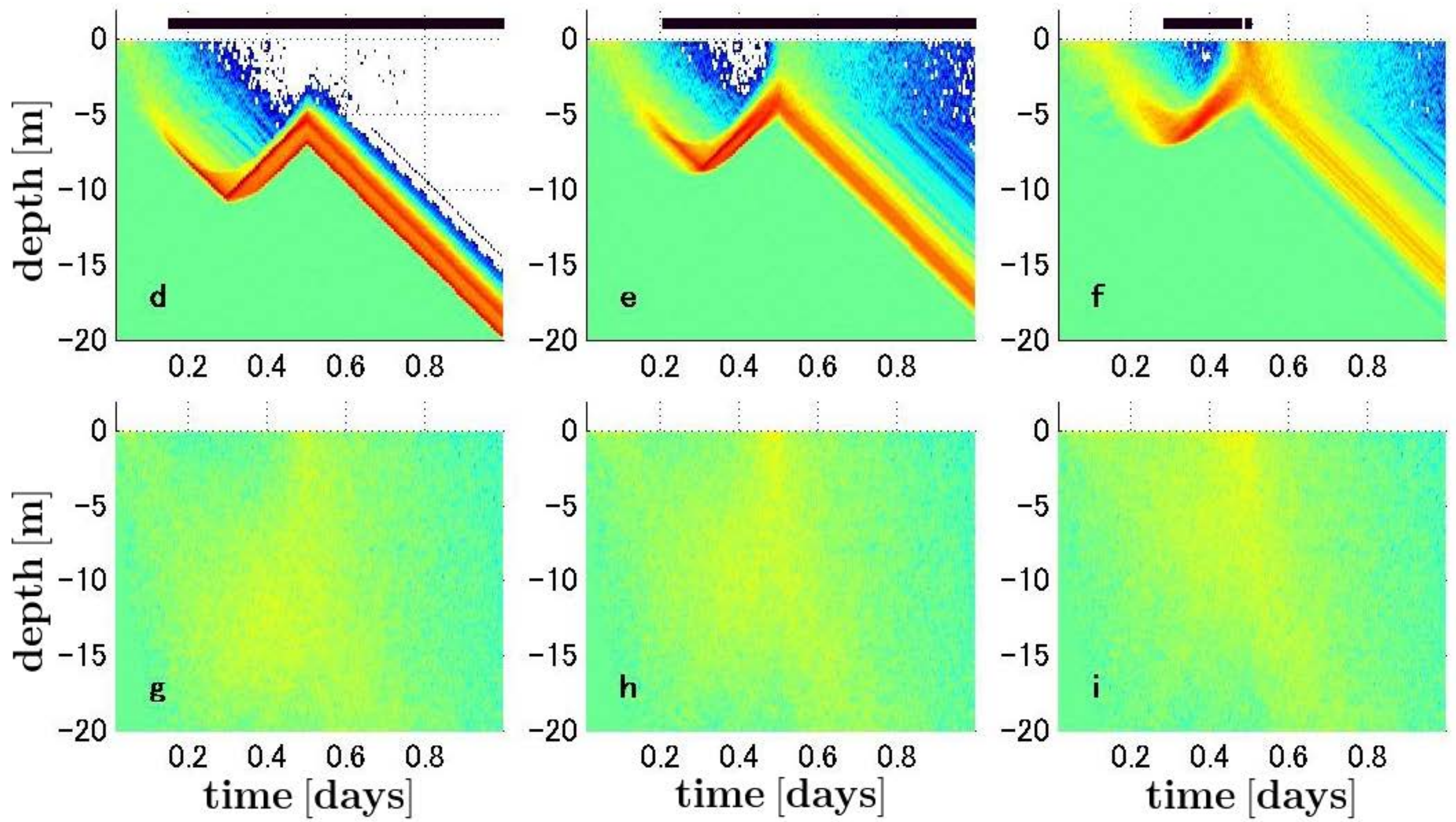
Figure 6
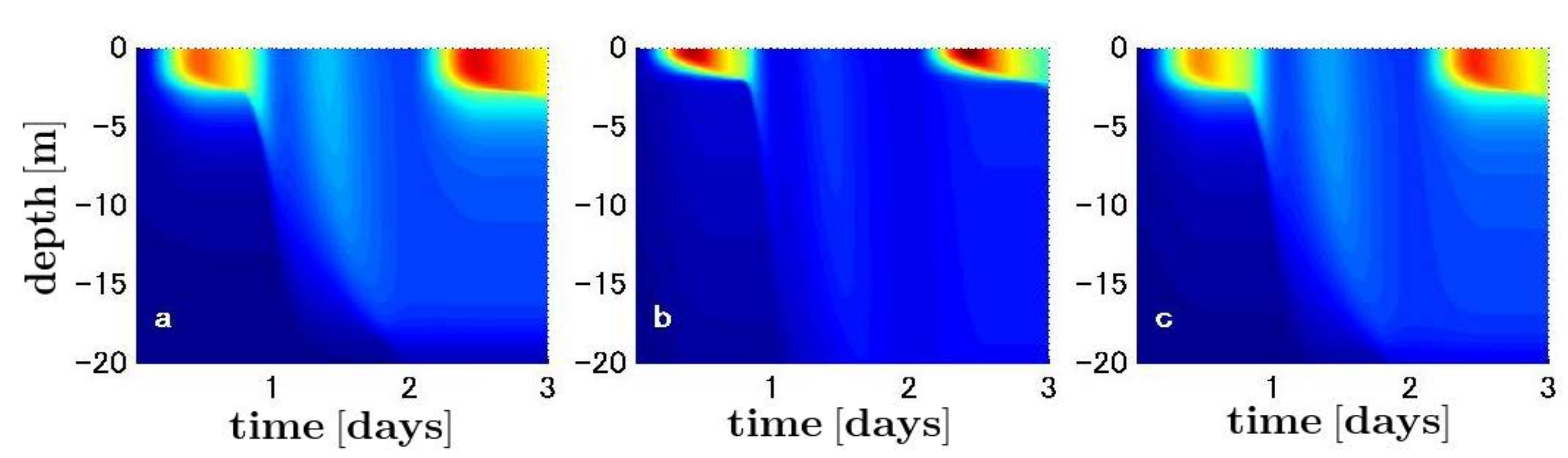

$\mathbf{T}\left[{ }^{\circ} \mathbf{C}\right]$

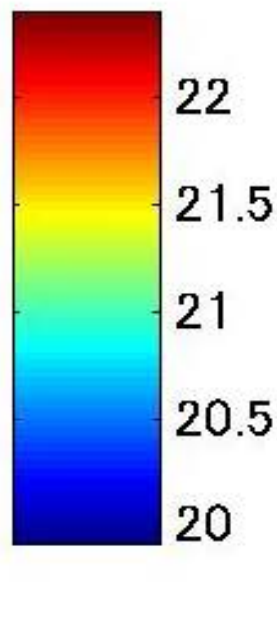


Figure 7
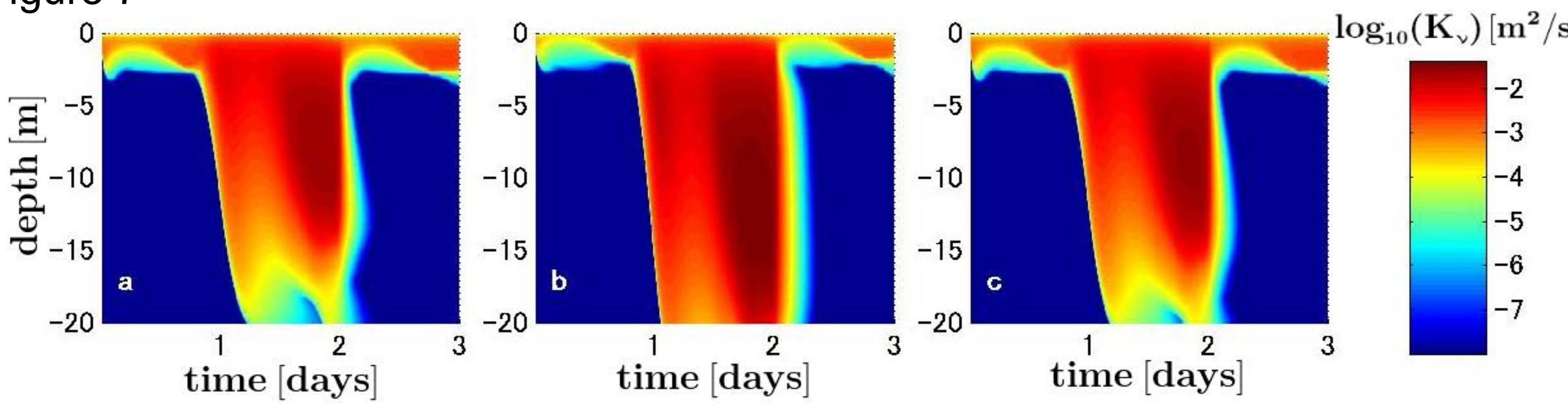
Figure 8
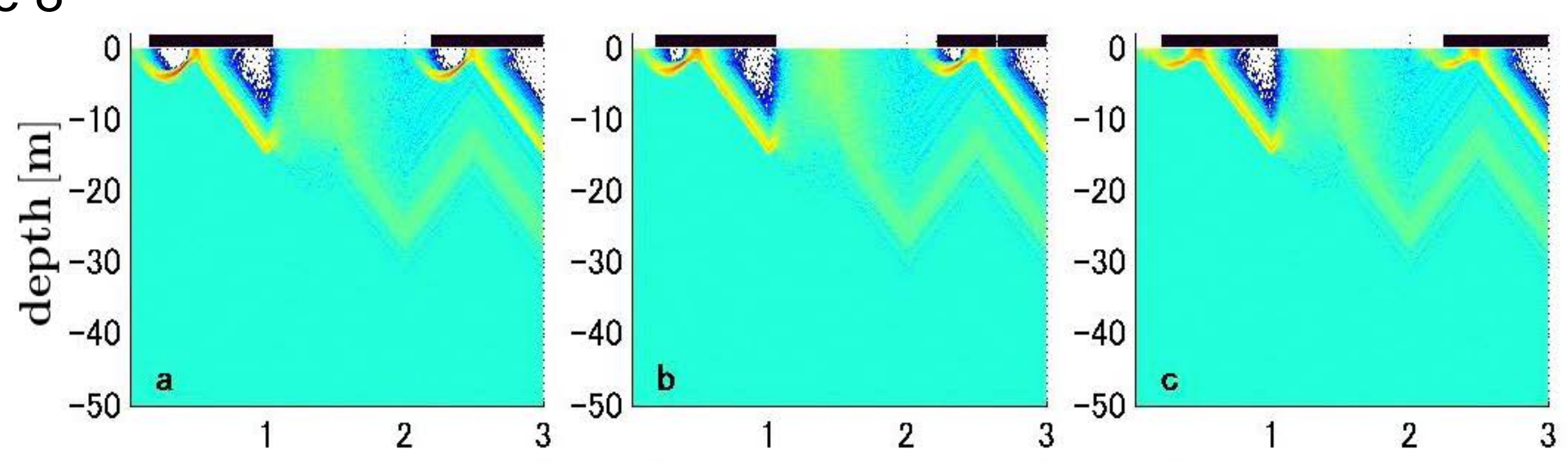

$\log _{10}\left(N_{p}\right)$
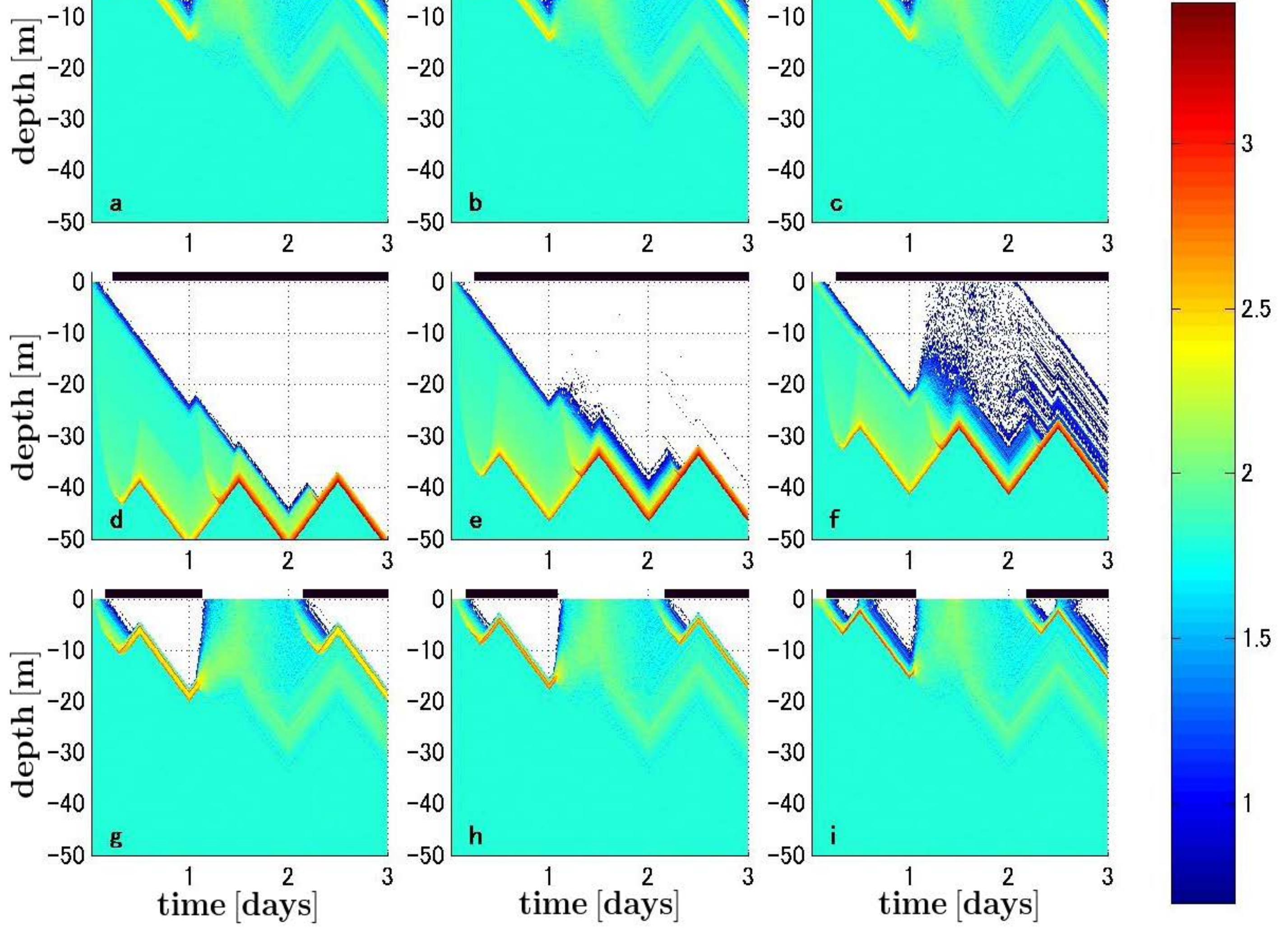
Figure 9

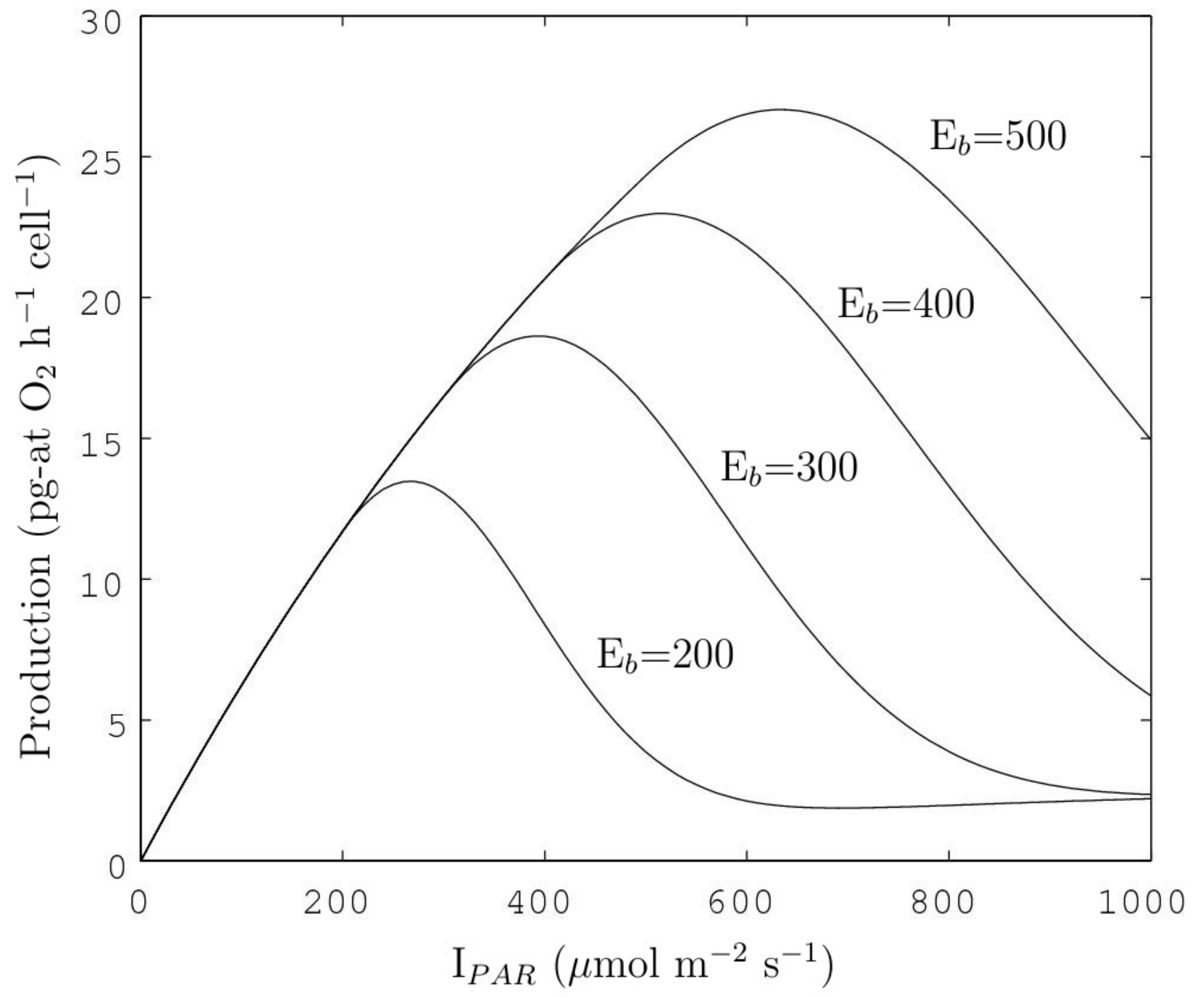


Figure 10

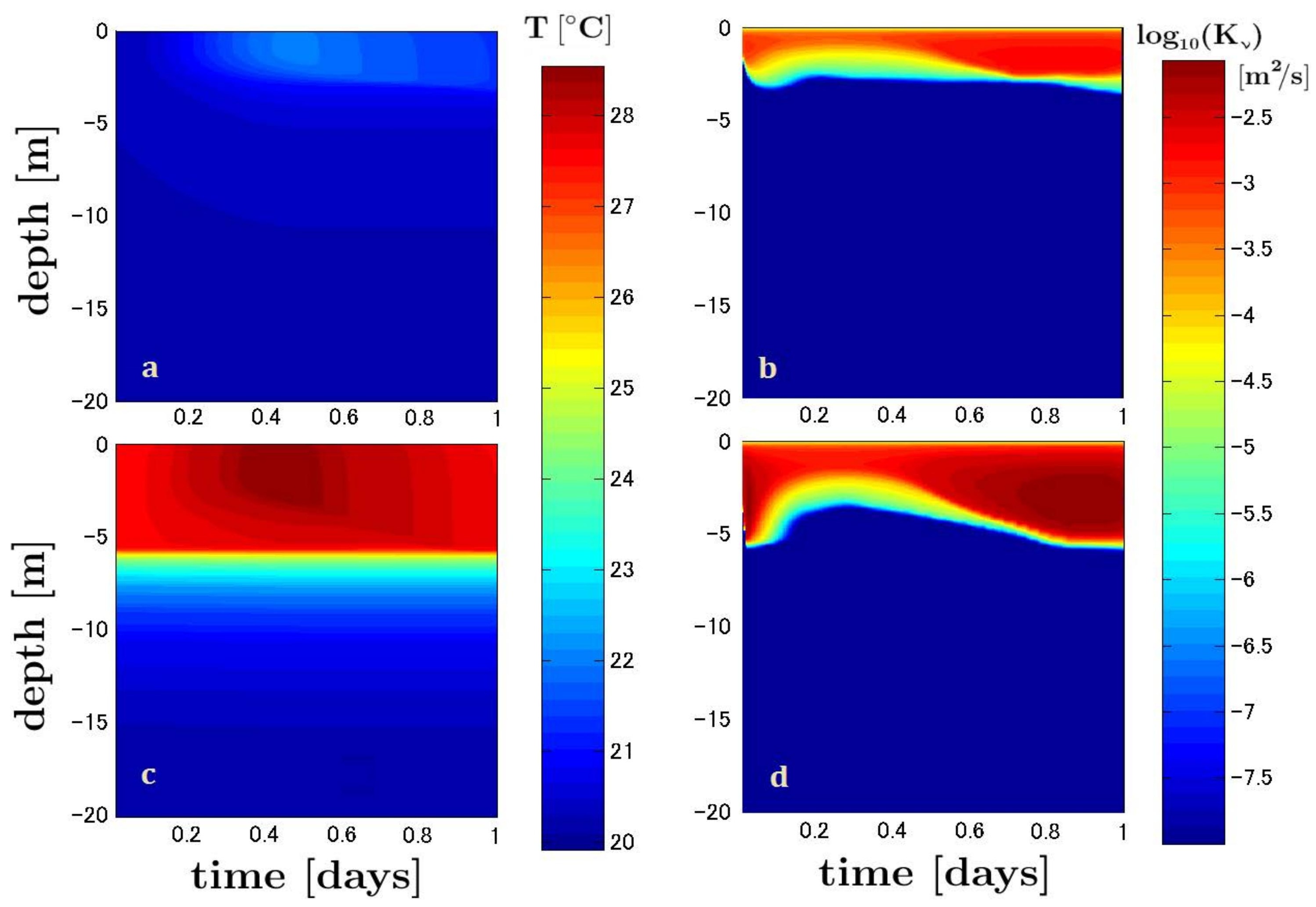




\section{Figure 11}
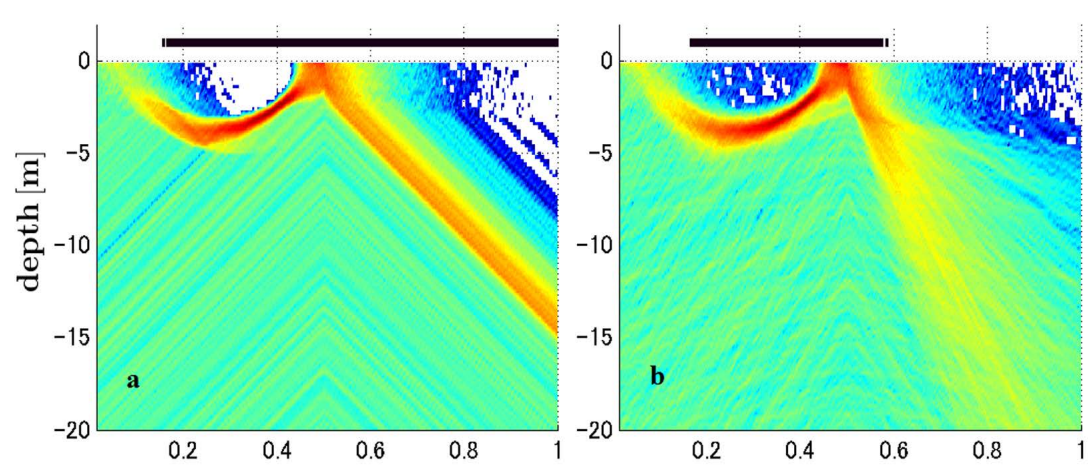

$\log _{10}\left(\mathrm{~N}_{\mathrm{p}}\right)$
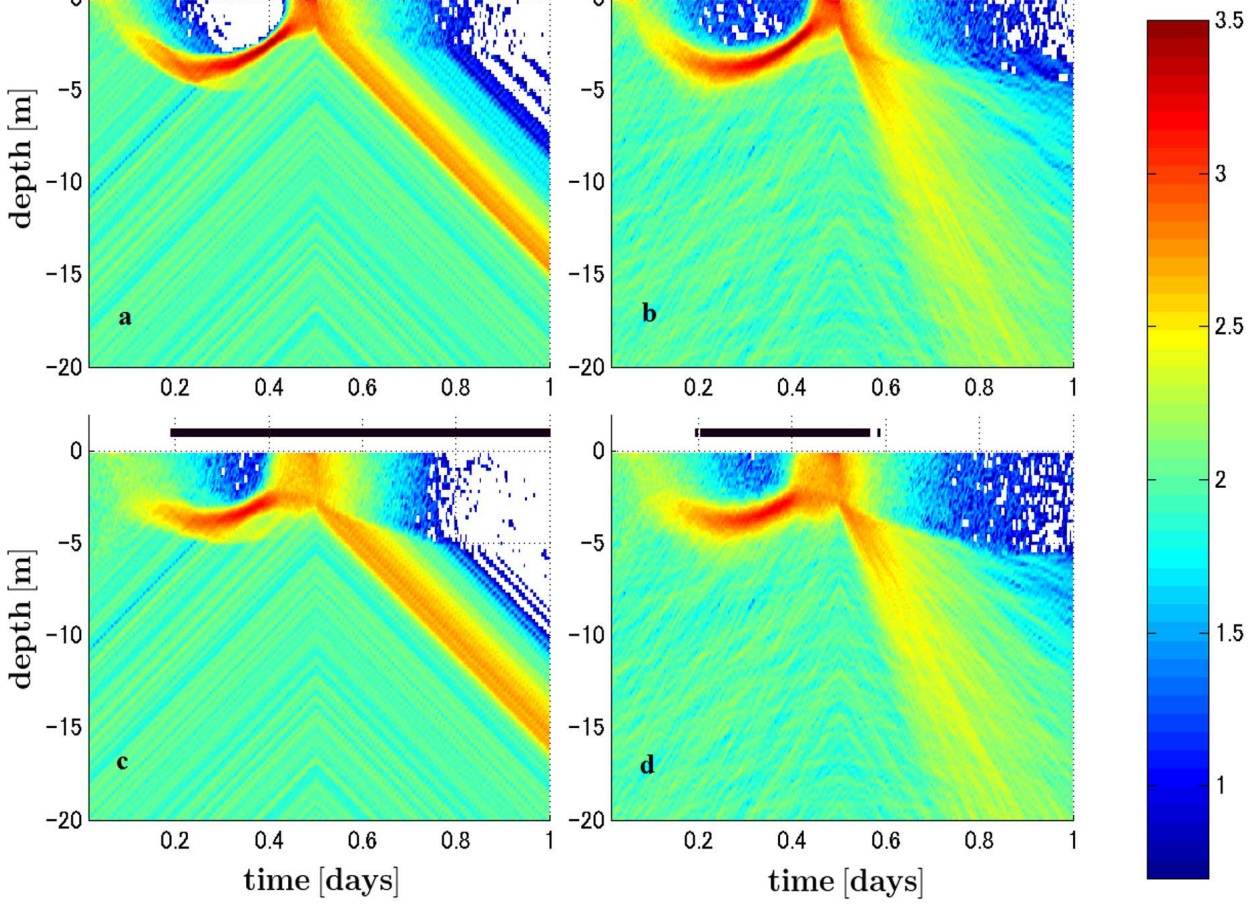


\section{Figure 12}

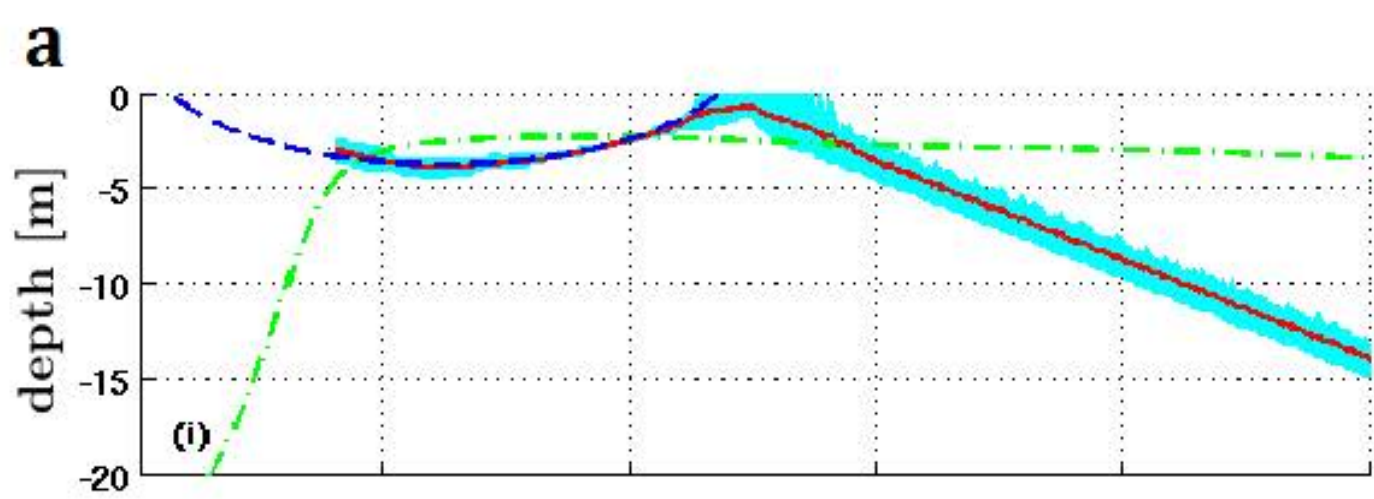

b
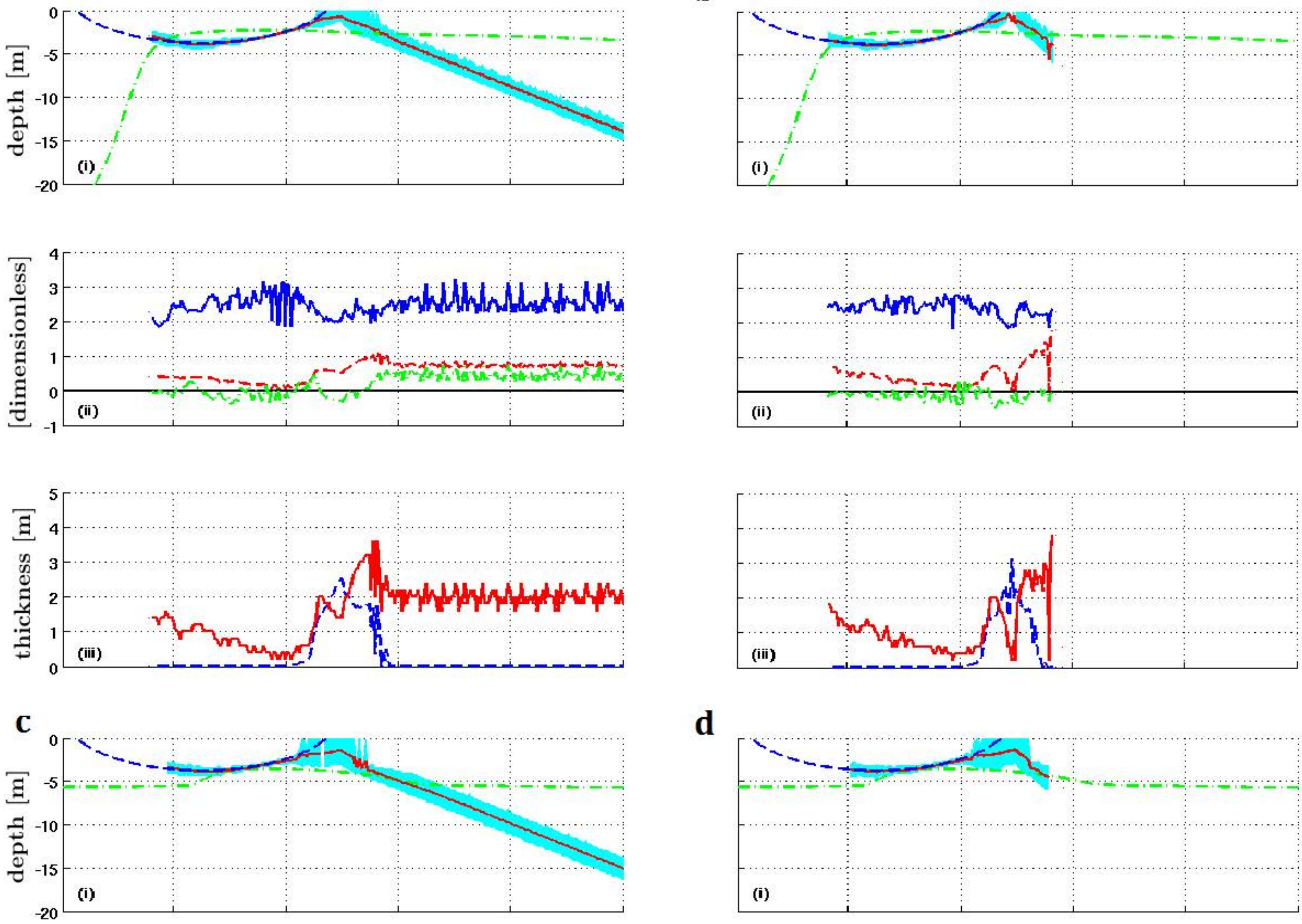

d
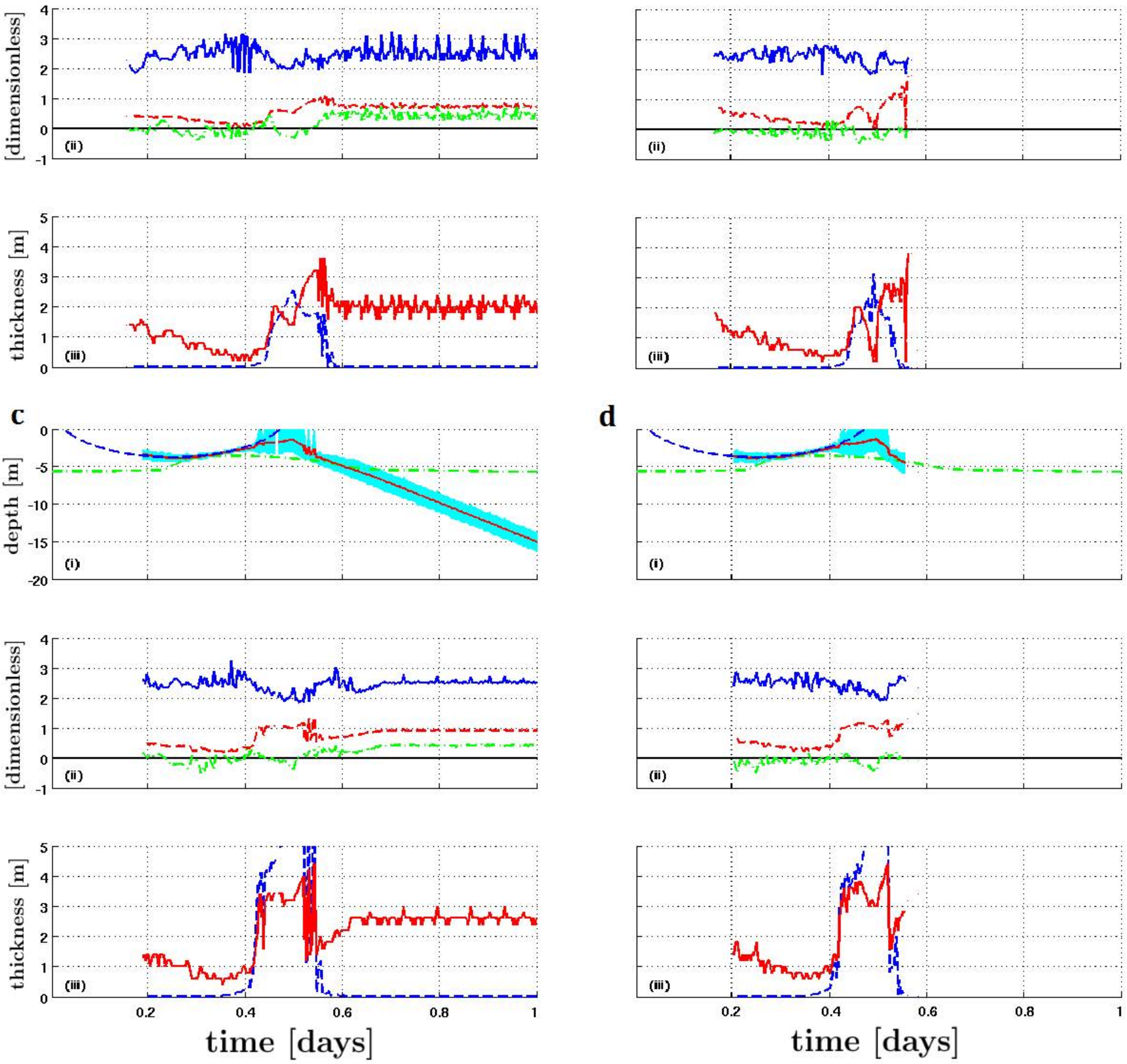